\title{
High-temperature creep of magnetite and ilmenite single crystals
}

\author{
J. L. Till ${ }^{1,2,3}$ [D $\cdot$ E. Rybacki ${ }^{1}$
}

Received: 7 July 2020 / Accepted: 20 October 2020 / Published online: 9 November 2020

(c) The Author(s) 2020

\begin{abstract}
We performed deformation experiments on dry natural single crystals of magnetite and ilmenite to determine the rheological behavior of these oxide minerals as a function of temperature, orientation, and oxygen fugacity. Samples were deformed at temperatures of $825-1150{ }^{\circ} \mathrm{C}$ to axial strains of up to $15-24 \%$ under approximately constant stress conditions up to $120 \mathrm{MPa}$ in a dead-load-type creep rig at ambient pressure in a controlled gas atmosphere. Oxygen fugacity ranged from $10^{-9.4}$ to $10^{-4}$ atm. Ilmenite creep was insensitive to oxygen fugacity, while magnetite displayed a strong, non-monotonic oxygen fugacity dependence, with creep rates varying as $f_{\mathrm{O}_{2}}^{-0.7}$ and $f_{\mathrm{O}_{2}}^{0.4}$ at more reducing and more oxidizing conditions, respectively. Dislocation creep rates of magnetite single crystals were weakly dependent on crystallographic orientation with stress exponents that varied between 2.8 and 4.3 (mean $3.5 \pm 0.4$ ). Magnetite compressed parallel to $\langle 100\rangle,\langle 110\rangle$, and $\langle 111\rangle$ axes exhibited apparent activation energies of $315 \pm 5,345 \pm 30$, and $290 \pm 5 \mathrm{~kJ} / \mathrm{mol}$, respectively. We estimated $f_{O 2}$-independent magnetite activation energies of $715 \pm 150,725 \pm 145$, and $690 \pm 150 \mathrm{~kJ} / \mathrm{mol}$ for $\langle 100\rangle,\langle 110\rangle$, and $\langle 111\rangle$ orientations, respectively, in the region of negative $f_{\mathrm{O}_{2}}$-dependence. Ilmenite single crystals were compressed parallel, normal, and inclined to the c-axis. Stress exponents of 3.4, 4.3, and 3.9 indicate dislocation creep with activation energies of $420 \pm 35,345 \pm 30$, and $360 \pm 40 \mathrm{~kJ} / \mathrm{mol}$, respectively, for these orientations. Mechanical anisotropy in ilmenite is notably higher than in magnetite, as expected from its lower crystal symmetry. Constitutive equations were formulated for ilmenite and magnetite creep.
\end{abstract}

Keywords Creep $\cdot$ Mineral physics $\cdot$ Fe-oxides $\cdot$ Experimental deformation

\section{Introduction}

The Fe-Ti oxides, magnetite and ilmenite, are widespread accessory minerals. The mechanical properties of these oxides can influence the deformation behavior of rocks where they occur in abundance, such as iron ore deposits (Zheng et al. 2017) and zones of intrusive igneous rocks where fractional crystallization results in Fe-Ti enrichment of magmas (Zhang et al. 2012). For example, oceanic gabbros formed at slow-spreading ridges frequently exhibit strain localization associated with $\mathrm{Fe}-\mathrm{Ti}$ oxiderich zones (Agar and Lloyd 1997; Dick et al. 2000, 2017).

J. L. Till

jtill@hi.is

1 Deutsches GeoForschungsZentrum Helmholz Zentrum Potsdam, Telegrafenberg, 14473 Potsdam, Germany

2 Institute of Earth Sciences, University of Iceland, Sturlugata 7, 101 Reykjavik, Iceland

3 Present Address: Institute for Rock Magnetism, University of Minnesota, Minneapolis, USA
Differentiation of the lunar magma ocean is also thought to have produced ilmenite-bearing cumulates (Charlier et al. 2018), whose deformation behavior would likely have depended on the viscosity of the ilmenite (Dygert et al. 2016).

In particular, for the analysis of naturally deformed $\mathrm{Fe}-\mathrm{Ti}$ oxide microstructures, creep data for single crystals of magnetite, ilmenite, and hematite are essential. However, relevant experimental data are currently limited. Dislocation and diffusion creep laws for (wet) magnetite were proposed by Till and Moskowitz (2013) based on theoretical considerations. More recently, Till et al. (2019) experimentally examined the creep behavior of (dry) polycrystalline magnetite aggregates. The textural development and creep strength of hematite have been studied in detail by Siemes et al. (2003, 2010, 2011), as well as single crystal deformation (Siemes et al. 2008). However, a study by Dygert et al. (2016) is the only one to report experimental deformation results for ilmenite, which was limited to the dislocation creep regime in synthetic ilmenite aggregates. Further data are needed for fined-grained and single crystalline ilmenite to better 
understand creep behavior in Fe-Ti oxide systems. In this paper, we present high-temperature experimental deformation data for natural magnetite and ilmenite single crystals including investigations of mechanical anisotropy and the dependence of strain rate on oxygen fugacity.

Magnetite $\left(\mathrm{Fe}_{3} \mathrm{O}_{4}\right)$ has an inverse spinel structure with an oxygen sublattice in a face-centered cubic (fcc) arrangement. The slip direction (Burgers vector) in spinel-structured materials is always parallel to the $<110>$ axes, which have the smallest distance between oxygen atoms. As in other fcc materials, the smallest interplanar spacing occurs between $\{111\}$ planes, which are predicted to be the easiest set of slip planes in spinels (Hornstra 1960). The \{111\} $1 \overline{10}$ group contains 12 slip systems, of which 5 are independent (Groves and Kelly 1963), satisfying the von Mises criterion for homogeneous strain. Therefore magnetite deforming by slip on $\{111\}$ does not require activation of any additional slip planes for homogeneous ductile deformation. While a number of experimental studies on spinel-structured minerals do find evidence for dominant slip on $\{111\}$ (Charpentier et al. 1968; Veyssiere et al. 1978; Siemes et al. 1991), several other studies have also found evidence for significant amounts of slip accommodated on $\{110\}$ and $\{100\}$ planes (Mishra and Thomas 1976; Duclos et al. 1978; Broese Van Groenou and Kadijk 1989). Stoichiometric magnetite contains both $\mathrm{Fe}^{2+}$ and $\mathrm{Fe}^{3+}$, and is stable at oxygen fugacities between the magnetite-hematite buffer and the magnetite-wustite buffer. Within this stability range, mass transport rates in magnetite are highly sensitive to oxygen fugacity (Van Orman and Crispin 2010) and magnetite creep rates have also shown a strong non-linear dependence (GómezGarcia et al. 2002).

Ilmenite $\left(\mathrm{TiFeO}_{3}\right)$ is a hexagonal oxide that is isostructural with hematite $\left(\alpha-\mathrm{Fe}_{2} \mathrm{O}_{3}\right)$ and corundum $\left(\mathrm{Al}_{2} \mathrm{O}_{3}\right)$, but has a lower symmetry $(\overline{3})$ than either hematite or corundum $(\overline{3} 2 / \mathrm{m})$ due to the alternating layers of $\mathrm{Fe}$ and $\mathrm{Ti}$ that occupy octahedral sites arranged parallel to the basal plane. At high temperatures, ilmenite forms a solid solution with hematite and often occurs in slowly cooled igneous rocks as lamellar intergrowths with hematite due to phase unmixing of hemoilmenite (McEnroe et al. 2002). It similarly forms intergrowths with magnetite due to oxyexsolution of titanomagnetite or ülvospinel on cooling (Andersen and Lindsley 1988). Hexagonal crystals in general typically display high mechanical anisotropy, with basal slip on (0001) being the easiest glide plane to activate, followed by prismatic slip on $\{10 \overline{1} 0\}$ (Hutchinson 1977). These two sets of planes contain four independent slip systems. Homogeneous strain in polycrystalline material may be achieved by additional slip on pyramidal planes $\{\mathrm{h} 0 \bar{i} 1\}$, or by the contribution of other deformation mechanisms such as twinning and grain boundary sliding. However, Hutchinson (1977) argues that in practice, individual grains in a polycrystal may deform at different rates than the bulk strain rate, as pyramidal slip is very difficult to activate.

\section{Starting materials and experimental methods}

\section{Sample details}

Magnetite samples for deformation experiments were produced from individual octahedral magnetite crystals from Bahia, Brazil. The composition of the starting materials was determined by electron microprobe analysis (EMPA) on a JEOL Hyperprobe JXA-8500F instrument with a fieldemission gun. The average composition of this magnetite as measured by EMPA in wt $\%$ oxides is $92.41 \% \mathrm{FeO}$ (with total $\mathrm{Fe}$ calculated as $\mathrm{FeO}$ ), $0.01 \% \mathrm{TiO}_{2}, 0.16 \% \mathrm{MgO}, 0.02 \%$ $\mathrm{MnO}, 0.08 \% \mathrm{Al}_{2} \mathrm{O}_{3}$, and $0.01 \% \mathrm{Cr}_{2} \mathrm{O}_{3}$ (total $=92.71 \%$ ), corresponding to a mole fraction of pure magnetite over $99.7 \%$. Small inclusions of Al-silicate, $\mathrm{Fe}-\mathrm{Mg}$-silicate, and $\mathrm{Ca}-$ carbonate were identified in the magnetite crystals, with an estimated volume of approximately $0.2 \%$ of the total sample. No cracks or other structural defects were observed in polished specimens of the starting material.

Ilmenite samples for creep experiments were cut from a large euhedral manganiferous ilmenite crystal from Kola, Russia. The EMPA composition of this material in wt $\%$ oxides is $39.05 \% \mathrm{FeO}$ (with total $\mathrm{Fe}$ calculated as $\mathrm{FeO}$ ), $51.68 \% \mathrm{TiO}_{2}, 0.05 \% \mathrm{MgO}, 6.77 \% \mathrm{MnO}, 0.02 \% \mathrm{Al}_{2} \mathrm{O}_{3}$, and $0.03 \% \mathrm{NaO}_{2}$ (total $=97.64 \%$ ).

Samples for creep experiments were prepared by drilling oriented cylinders (2-mm diameter, 4-mm length) from individual magnetite octahedra (Fig. 1a) and by cutting the ilmenite single crystal into oriented rectangular blocks with lengths of 4-6 mm and widths of $2 \times 2 \mathrm{~mm}$, using the crystal faces as reference orientations (Fig. 1b). Three sample orientations were used for each material. Magnetite crystals were compressed parallel to either $\langle 100\rangle,\langle 110\rangle$, or $<111>$ directions. Ilmenite crystals were compressed along the $\langle\mathrm{c}\rangle$ axis (perpendicular to the basal plane), normal to the $<\mathrm{c}>$ axis (parallel to the $<\mathrm{a}>$ axis), or at an approximately $45^{\circ}$ angle to both the $<\mathrm{c}>$ axis and the $<\mathrm{a}>$ axis.

\section{Experimental procedures}

Creep experiments were performed in a uniaxial dead load creep rig (Freund et al. 2004) at ambient pressure of approximately $0.1 \mathrm{MPa}$ in a controlled gas atmosphere. Piston displacement was recorded by a linear voltage differential transducer with $0.2 \mu \mathrm{m}$ resolution, which was used to calculate sample strains and strain rates. Load was applied to a leveraged platform in the form of steel plates in increments of approximately $32 \mathrm{~N}$. Creep experiments were conducted 
(a)

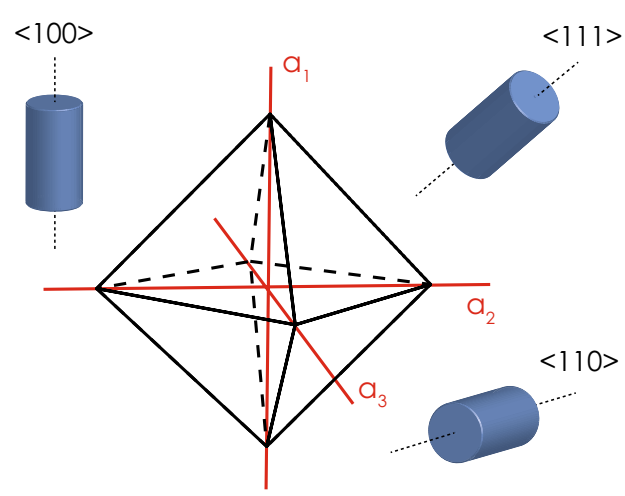

(b)

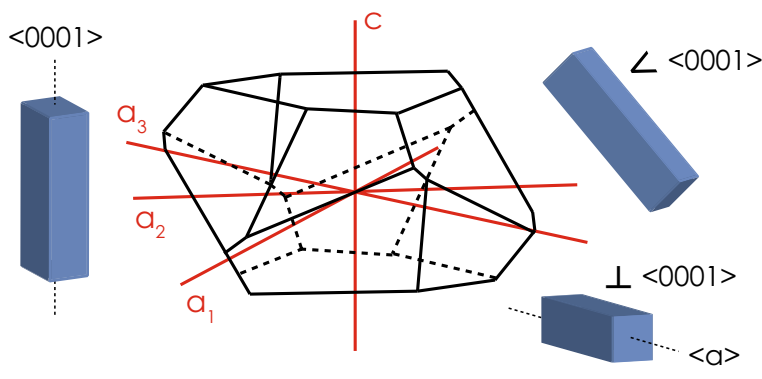

Fig. 1 Diagrams illustrating sample orientations used for creep experiments from a magnetite and $\mathbf{b}$ ilmenite single crystals

at temperatures between 825 and $1150^{\circ} \mathrm{C}$ under applied axial stresses of 8-120 MPa. The samples were separated from the pistons with alumina spacers and a thin layer of finely powdered boron nitride made into a paste to facilitate removal of the sample after the experiments. Boron nitride is highly refractory and is not expected to creep at the temperature range of our experiments. The calibrated temperature gradient of the furnace is approximately $3{ }^{\circ} \mathrm{C}$ across the length of the sample in the temperature range $800-1200^{\circ} \mathrm{C}$. Each specimen was deformed at several temperature steps in decreasing order and several load steps in increasing order at each temperature.

For load-stepping experiments, a flowing gas atmosphere composed of $\mathrm{CO}_{2}$ mixed with $3 \% \mathrm{H}_{2}$ was used. This gas mixture produces an oxygen fugacity close to that of the quartz-fayalite-magnetite (QFM) buffer over the temperature range of our experiments (Huebner and Sato 1970; Prunier and Hewitt 1981). Gas was allowed to flow through the sealed vessel for several hours prior to the start of the experiment to thoroughly flush out excess oxygen. To investigate the influence of oxygen fugacity on magnetite deformation, a series of experiments was performed in the creep assembly under constant load at select temperatures with varying concentrations of $\mathrm{H}_{2}$ mixed with $\mathrm{CO}_{2}$ gas. Tabulated values of $\mathrm{H}_{2}$ and $\mathrm{CO}_{2}$ mixtures corresponding to target oxygen fugacity $\left(f_{\mathrm{O}_{2}}\right)$ values from Prunier and Hewitt
(1981) were used to calculate the proportional flow rates for a pre-mixed $\mathrm{CO}_{2}$ gas containing $3 \%$ hydrogen mixed with pure $\mathrm{CO}_{2}$. After each change in gas composition, the sample was unloaded and the gas was allowed to flow through the furnace for at least $20 \mathrm{~min}$ before reloading to stabilize the atmosphere. Steady-state creep rates were observed following each change in atmosphere; however, it should be noted that point defect structures in olivine have been observed to require substantially longer times to respond to changes in $f_{\mathrm{O}_{2}}$ (Mackwell et al. 1988). For creep tests of $f_{\mathrm{O}_{2}}$-dependence, a single crystal of magnetite was compressed parallel to $<111>$ under axial stresses around 35 and $65 \mathrm{MPa}$ at temperatures of $1100^{\circ}$ and $1150^{\circ}$ (Table 1) and an ilmenite single crystal sample was compressed normal to $<0001>$ under an axial stress around $46 \mathrm{MPa}$ at $1150^{\circ} \mathrm{C}$ (Table 2).

Initial sample dimensions were precisely measured prior to each experiment. A data-processing algorithm was used to calculate the axial stresses in each load step by correcting for the increase in cross-sectional area of the sample during shortening, assuming uniform shortening and constant volume. Load steps were usually limited to increments of $1 \%$ strain after reaching steady-state flow conditions. Total strains achieved in each experiments were less than $15 \%$ except for experiment JM06, where the final strain was $24 \%$. Representative curves of load and displacement vs. time are shown in Fig. 2 for several $1100^{\circ} \mathrm{C}$ steps for magnetite and ilmenite.

After each experiment, deformed samples were sectioned in half along the compression axis, mounted in epoxy, and polished for microscopic analysis. All deformed samples were examined for evidence of oxidation, alteration or chemical reaction in polished sections using reflected light optical microscopy. Transmission electron microscopy (TEM) was performed on representative deformed samples to image dislocations and deformation microstructures. TEM foils were prepared with the focused ion beam (FIB) technique and imaged in diffraction contrast mode on a Tecnai G2 F20 $\mathrm{X}$-Twin TEM equipped with a field-emission gun.

\section{Results}

\section{Deformation microstructures}

The main defects identified in TEM analysis of deformed magnetite from experiment JM06 were narrow slip bands (Fig. 3a). Free dislocations were rare in the TEM foils examined from this sample. The formation of slip bands and highly inhomogeneous distribution of defects has been noted in Ni-ferrite spinel crystals by Rabier et al. (1976), in natural magnetite crystals experimentally deformed by Lindquist et al. (2015) and Hennig-Michaeli and Siemes (1982), as well as in naturally deformed 
Table 1 Magnetite singlecrystal creep experiment conditions and results

\begin{tabular}{|c|c|c|c|c|c|c|}
\hline Experiment & $\begin{array}{l}\text { Compression } \\
\text { direction }\end{array}$ & Temp ${ }^{\circ} \mathrm{C}$ & $\sigma(\mathrm{MPa})$ & $\log . \dot{\epsilon} 1 / \mathrm{s}$ & $\%$ strain & $\log f_{O_{2}}(\mathrm{~atm})$ \\
\hline \multirow[t]{9}{*}{ JM03 } & \multirow[t]{9}{*}{$<100>$} & 825 & 69.4 & -7.32 & 1.2 & -14.8 \\
\hline & & 825 & 93.2 & -6.88 & 2.3 & -14.8 \\
\hline & & 825 & 116 & -6.58 & 3.1 & -14.8 \\
\hline & & 880 & 51.6 & -6.75 & 3.9 & -13.5 \\
\hline & & 880 & 75.1 & -6.35 & 4.7 & -13.5 \\
\hline & & 880 & 97.9 & -5.95 & 5.6 & -13.5 \\
\hline & & 880 & 120 & -5.63 & 6.5 & -13.5 \\
\hline & & 938 & 49.6 & -6.77 & 7.4 & -12.3 \\
\hline & & 938 & 79.7 & -5.85 & 8.3 & -12.3 \\
\hline \multirow[t]{13}{*}{ JM04 } & \multirow[t]{13}{*}{$<111>$} & 1094 & 30.1 & -6.20 & 1.4 & -9.5 \\
\hline & & 1094 & 43.8 & -5.59 & 2.2 & -9.5 \\
\hline & & 1094 & 57.2 & -5.22 & 3.0 & -9.5 \\
\hline & & 1043 & 43.2 & -6.03 & 3.6 & -10.3 \\
\hline & & 1043 & 29.2 & -6.71 & 4.0 & -10.3 \\
\hline & & 1043 & 56.2 & -5.75 & 5.0 & -10.3 \\
\hline & & 990 & 21.9 & -7.52 & 5.8 & -11.2 \\
\hline & & 990 & 55.3 & -6.25 & 6.4 & -11.2 \\
\hline & & 990 & 74.7 & -5.76 & 7.3 & -11.2 \\
\hline & & 990 & 92.7 & -5.40 & 10.1 & -11.2 \\
\hline & & 938 & 65.2 & -6.50 & 11.2 & -12.3 \\
\hline & & 938 & 90.0 & -6.01 & 12.0 & -12.3 \\
\hline & & 938 & 114 & -5.64 & 13.0 & -12.3 \\
\hline \multirow[t]{12}{*}{ JM05 } & \multirow[t]{12}{*}{$<110>$} & 1145 & 26.5 & -5.62 & 2.4 & -8.8 \\
\hline & & 1145 & 38.7 & -5.15 & 2.9 & -8.8 \\
\hline & & 1145 & 50.7 & -4.78 & 3.5 & -8.8 \\
\hline & & 1095 & 32.0 & -5.90 & 4.0 & -9.5 \\
\hline & & 1095 & 49.8 & -5.28 & 4.6 & -9.5 \\
\hline & & 1095 & 67.5 & -4.83 & 5.3 & -9.5 \\
\hline & & 1044 & 48.4 & -6.02 & 6.4 & -10.3 \\
\hline & & 1044 & 65.2 & -5.47 & 7.3 & -10.3 \\
\hline & & 1044 & 81.7 & -5.07 & 8.3 & -10.3 \\
\hline & & 990 & 57.8 & -6.02 & 9.3 & -11.2 \\
\hline & & 990 & 79.7 & -5.63 & 10.3 & -11.2 \\
\hline & & 990 & 100.8 & -5.34 & 11.1 & -11.2 \\
\hline \multirow[t]{16}{*}{ JM06 } & \multirow[t]{16}{*}{$<100>$} & 1143 & 35.1 & -4.78 & 2.3 & -8.8 \\
\hline & & 1143 & 26.5 & -5.32 & 3.4 & -8.8 \\
\hline & & 1143 & 42.3 & -4.69 & 4.4 & -8.8 \\
\hline & & 1143 & 49.5 & -4.45 & 5.1 & -8.8 \\
\hline & & 1094 & 17.7 & -6.44 & 5.6 & -9.5 \\
\hline & & 1094 & 33.1 & -5.54 & 6.5 & -9.5 \\
\hline & & 1094 & 48.2 & -4.97 & 7.5 & -9.5 \\
\hline & & 1094 & 62.9 & -4.56 & 8.2 & -9.5 \\
\hline & & 1094 & 77.2 & -4.22 & 9.2 & -9.5 \\
\hline & & 1042 & 46.4 & -5.40 & 10.2 & -10.3 \\
\hline & & 1042 & 23.6 & -6.79 & 11.3 & -10.3 \\
\hline & & 1042 & 38.2 & -5.86 & 12.2 & -10.3 \\
\hline & & 1042 & 59.6 & -5.10 & 13.2 & -10.3 \\
\hline & & 1042 & 73.3 & -4.73 & 13.8 & -10.3 \\
\hline & & 990 & 51.1 & -5.87 & 15.0 & -11.2 \\
\hline & & 990 & 64.4 & -5.44 & 16.0 & -11.2 \\
\hline
\end{tabular}


Table 1 (continued)

\begin{tabular}{|c|c|c|c|c|c|c|}
\hline Experiment & $\begin{array}{l}\text { Compression } \\
\text { direction }\end{array}$ & Temp ${ }^{\circ} \mathrm{C}$ & $\sigma(\mathrm{MPa})$ & $\log . \dot{\epsilon} 1 / \mathrm{s}$ & $\%$ strain & $\log f_{\mathrm{O}_{2}}(\mathrm{~atm})$ \\
\hline & & 990 & 77.3 & -5.10 & 17.0 & -11.2 \\
\hline & & 990 & 89.9 & -4.82 & 17.8 & -11.2 \\
\hline & & 936 & 68.9 & -5.83 & 18.5 & -12.3 \\
\hline & & 936 & 47.9 & -6.58 & 20.7 & -12.3 \\
\hline & & 936 & 60.3 & -6.17 & 21.7 & -12.3 \\
\hline & & 936 & 72.5 & -5.82 & 22.6 & -12.3 \\
\hline & & 936 & 84.2 & -5.55 & 23.6 & -12.3 \\
\hline \multirow[t]{15}{*}{ JM07 } & $<111>$ & 1150 & 37.6 & -4.99 & 1.8 & -8.8 \\
\hline & & 1150 & 36.8 & -5.37 & 2.5 & -8.0 \\
\hline & & 1150 & 36.7 & -6.24 & 3.0 & -7.0 \\
\hline & & 1150 & 36.2 & -5.90 & 3.7 & -6.0 \\
\hline & & 1150 & 35.8 & -5.47 & 4.5 & -5.0 \\
\hline & & 1150 & 35.5 & -5.45 & 5.1 & -4.0 \\
\hline & & 1100 & 35.0 & -6.83 & 6.2 & -8.0 \\
\hline & & 1100 & 34.7 & -5.94 & 6.6 & -9.4 \\
\hline & & 1100 & 66.8 & -5.01 & 7.0 & -9.4 \\
\hline & & 1100 & 66.3 & -5.49 & 8.2 & -9.0 \\
\hline & & 1100 & 66.1 & -5.92 & 8.6 & -8.6 \\
\hline & & 1100 & 65.9 & -6.09 & 9.0 & -8.0 \\
\hline & & 1100 & 65.4 & -6.05 & 9.4 & -7.0 \\
\hline & & 1100 & 64.7 & -5.37 & 10.4 & -6.0 \\
\hline & & 1100 & 64.5 & -5.30 & 11.3 & -5.0 \\
\hline
\end{tabular}

magnetite by Mamtani et al. (2020), who additionally observed stacking faults, nanotwins, and evidence of recrystallization in TEM imaging. TEM images of deformed ilmenite from experiment KI03 (Fig. 3b) mainly contain short, straight dislocations arranged into incipient low-angle boundaries with a relatively low density of free dislocations.

\section{Creep of magnetite single crystals}

Axial strain rates in all experiments ranged from $3 \times 10^{-8}$ to $6 \times 10^{-5} \mathrm{~s}^{-1}$ for applied stresses between 20 and $120 \mathrm{MPa}$ (Table 1). For data analysis, we assumed power law creep behavior of the form $\dot{\epsilon}=A \sigma^{n} f_{O_{2}}^{r} \exp \{-Q / R T\}$, where $\dot{\epsilon}$ is strain rate in s ${ }^{-1}, A$ is a material-dependent pre-exponential factor, $\sigma$ is the axial stress in $\mathrm{MPa}, n$ is the stress exponent, $f_{\mathrm{O}_{2}}$ is oxygen fugacity in atm, $r$ is the fugacity exponent, and $Q$ is the activation energy in $\mathrm{kJ} / \mathrm{mol}$.

All load-stepping segments exhibited steady-state creep behavior with stress exponents ranging between 2.8 and 4.3 independent of sample orientation (Figure 4) with a mean value of $3.5 \pm 0.4$, consistent with dislocation creep. Evidently, at a given temperature, samples deformed parallel to $<100>$ are weaker than those compressed along the $<110>$ and $<111>$ directions. Activation energies were calculated by taking the mean stress exponent from the creep segments at each temperature, extrapolating the strain rates for a stress of $100 \mathrm{MPa}$, then plotting the strain rates on an Arrhenius diagram (Figure 5). Figure 5 also contains data for 1-atm creep experiments on magnetite single crystals from Lindquist et al. (2015) and Gómez-Garcia et al. (2002), who investigated creep rates as a function of oxygen fugacity. Also shown are experimental creep data for Mn-Zn ferrite single crystals from Nishikawa et al. (1981b) as cited in Okamoto (1989), performed in a bending apparatus.

Compression along $<100>$ was found to be the weakest orientation, for which we determined a mean stress exponent of $3.6 \pm 0.5$ and an activation energy of $315 \pm 5 \mathrm{~kJ} / \mathrm{mol}$. Single crystals compressed along $<110>$ exhibited a mean stress exponent of $3.3 \pm 0.6$ and an activation energy of $345 \pm 30 \mathrm{~kJ} / \mathrm{mol}$. Compression along $<111>$ exhibited similar strengths to the $<110>$ orientation, with a mean stress exponent of $3.5 \pm 0.4$ and activation energy of $290 \pm 5 \mathrm{~kJ} /$ mol. Within the uncertainties, the stress exponents for each orientation are indistinguishable, and the activation energies nearly overlap. The above creep parameters correspond to pre-exponential factors of $A=14.2,158$, and $0.725 \mathrm{MPa}^{-n}$ for compression along $<100>,<110>$, and $<111>$, respectively, without accounting for creep dependence on oxygen fugacity (see Sect. 3.4). 
Table 2 Ilmenite single-crystal creep experiment conditions and results

\begin{tabular}{|c|c|c|c|c|c|c|}
\hline Experiment & Compression direction & Temp ${ }^{\circ} \mathrm{C}$ & $\sigma(\mathrm{MPa})$ & $\log \dot{\epsilon} 1 / \mathrm{s}$ & $\%$ strain & $\log f_{\mathrm{O}_{2}}(\mathrm{~atm})$ \\
\hline \multirow[t]{17}{*}{ KI03 } & \multirow[t]{17}{*}{ Angle to $<0001>$} & 1100 & 15.9 & -4.67 & 1.4 & -9.4 \\
\hline & & 1100 & 8.7 & -5.82 & 2.1 & -9.4 \\
\hline & & 1100 & 15.6 & -4.97 & 2.7 & -9.4 \\
\hline & & 1100 & 22.4 & -4.37 & 3.2 & -9.4 \\
\hline & & 1050 & 22.0 & -5.14 & 4.2 & -10.2 \\
\hline & & 1050 & 35.3 & -4.08 & 5.0 & -10.2 \\
\hline & & 1050 & 28.2 & -4.33 & 5.7 & -10.2 \\
\hline & & 1050 & 14.5 & -5.60 & 6.4 & -10.2 \\
\hline & & 1000 & 14.2 & -6.22 & 6.6 & -11.1 \\
\hline & & 1000 & 27.2 & -5.09 & 8.0 & -11.1 \\
\hline & & 1000 & 39.7 & -3.52 & 9.2 & -11.1 \\
\hline & & 950 & 26.4 & -5.46 & 10.0 & -12.0 \\
\hline & & 950 & 32.6 & -4.89 & 10.8 & -12.0 \\
\hline & & 950 & 38.6 & -4.36 & 11.6 & -12.0 \\
\hline & & 950 & 13.2 & -7.10 & 12.2 & -12.0 \\
\hline & & 900 & 31.7 & -6.33 & 12.8 & -13.0 \\
\hline & & 900 & 43.6 & -4.75 & 13.6 & -13.0 \\
\hline \multirow[t]{13}{*}{ KI04 } & \multirow[t]{13}{*}{$<0001>$} & 1144 & 34.4 & -6.16 & 1.5 & -8.8 \\
\hline & & 1144 & 47.1 & -5.82 & 1.9 & -8.8 \\
\hline & & 1144 & 59.9 & -5.45 & 2.1 & -8.8 \\
\hline & & 1093 & 40.5 & -6.68 & 2.3 & -9.5 \\
\hline & & 1093 & 59.5 & -6.12 & 2.7 & -9.5 \\
\hline & & 1093 & 84.9 & -5.68 & 3.1 & -9.5 \\
\hline & & 1043 & 39.8 & -7.36 & 3.8 & -10.3 \\
\hline & & 1043 & 58.6 & -6.85 & 3.9 & -10.3 \\
\hline & & 1043 & 77.2 & -6.48 & 4.1 & -10.3 \\
\hline & & 1043 & 102 & -5.94 & 4.5 & -10.3 \\
\hline & & 990 & 64.0 & -7.27 & 4.7 & -11.2 \\
\hline & & 990 & 88.5 & -6.77 & 5.0 & -11.2 \\
\hline & & 990 & 113 & -6.29 & 5.2 & -11.2 \\
\hline \multirow[t]{18}{*}{ KI05 } & \multirow[t]{18}{*}{ Normal to $<0001>$} & 1100 & 28.7 & -6.57 & 1.1 & -9.4 \\
\hline & & 1100 & 48.7 & -5.89 & 1.4 & -9.4 \\
\hline & & 1100 & 21.7 & -7.30 & 1.6 & -9.4 \\
\hline & & 1150 & 28.2 & -6.34 & 1.9 & -8.7 \\
\hline & & 1150 & 40.8 & -5.76 & 2.4 & -8.7 \\
\hline & & 1150 & 53.4 & -5.22 & 3.5 & -8.7 \\
\hline & & 1150 & 65.6 & -4.82 & 4.6 & -8.7 \\
\hline & & 1050 & 33.5 & -7.22 & 5.5 & -10.2 \\
\hline & & 1050 & 52.4 & -6.44 & 5.9 & -10.2 \\
\hline & & 1050 & 70.6 & -5.76 & 6.4 & -10.2 \\
\hline & & 1050 & 88.6 & -5.20 & 7.3 & -10.2 \\
\hline & & 1000 & 75.8 & -6.10 & 8.2 & -11.1 \\
\hline & & 1000 & 100 & -5.57 & 8.5 & -11.1 \\
\hline & & 1000 & 38.0 & -7.39 & 9.2 & -11.1 \\
\hline & & 1100 & 50.2 & -5.54 & 10.2 & -9.4 \\
\hline & & 1100 & 61.4 & -5.03 & 11.2 & -9.4 \\
\hline & & 1100 & 37.1 & -5.98 & 12.0 & -9.4 \\
\hline & & 1100 & 25.0 & -6.61 & 13.2 & -9.4 \\
\hline
\end{tabular}


Table 2 (continued)

\begin{tabular}{|c|c|c|c|c|c|c|}
\hline Experiment & Compression direction & Temp ${ }^{\circ} \mathrm{C}$ & $\sigma(\mathrm{MPa})$ & $\log \dot{\epsilon} 1 / \mathrm{s}$ & $\%$ strain & $\log f_{\mathrm{O}_{2}}(\mathrm{~atm})$ \\
\hline \multirow[t]{7}{*}{ KI06 } & \multirow[t]{7}{*}{ Normal to $<0001>$} & 1150 & 46.4 & -5.80 & 1.5 & -8 \\
\hline & & 1150 & 45.8 & -5.75 & 2.4 & -7 \\
\hline & & 1150 & 44.9 & -5.73 & 3.1 & -8 \\
\hline & & 1150 & 45.0 & -5.81 & 3.8 & -8.7 \\
\hline & & 1150 & 44.2 & -5.69 & 5.3 & -6 \\
\hline & & 1150 & 43.5 & -5.37 & 6.6 & -5 \\
\hline & & 1150 & 43.2 & -5.23 & 6.9 & -6 \\
\hline
\end{tabular}

(a)
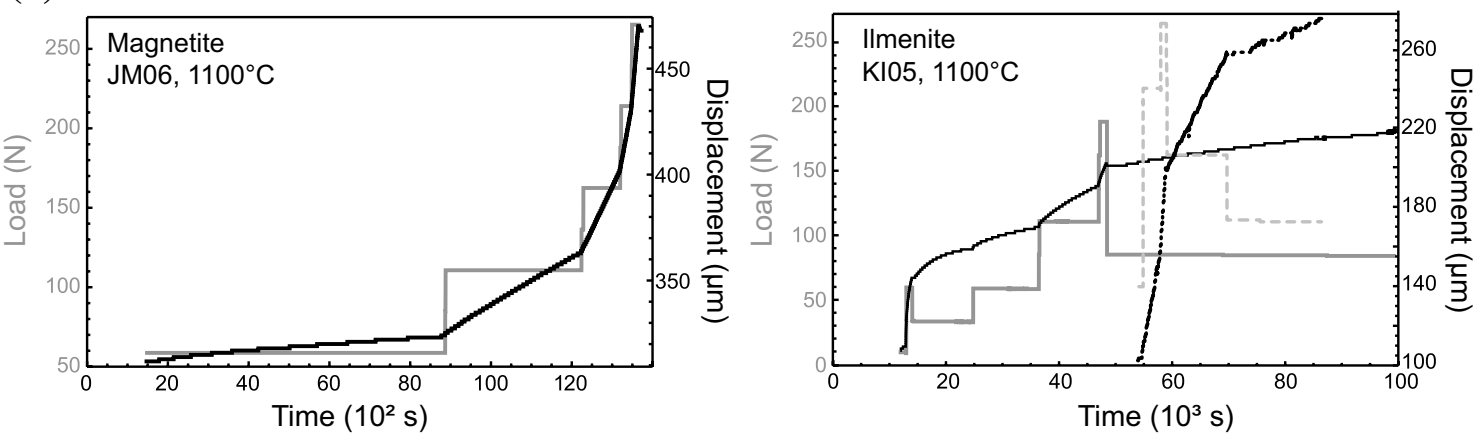

(b)
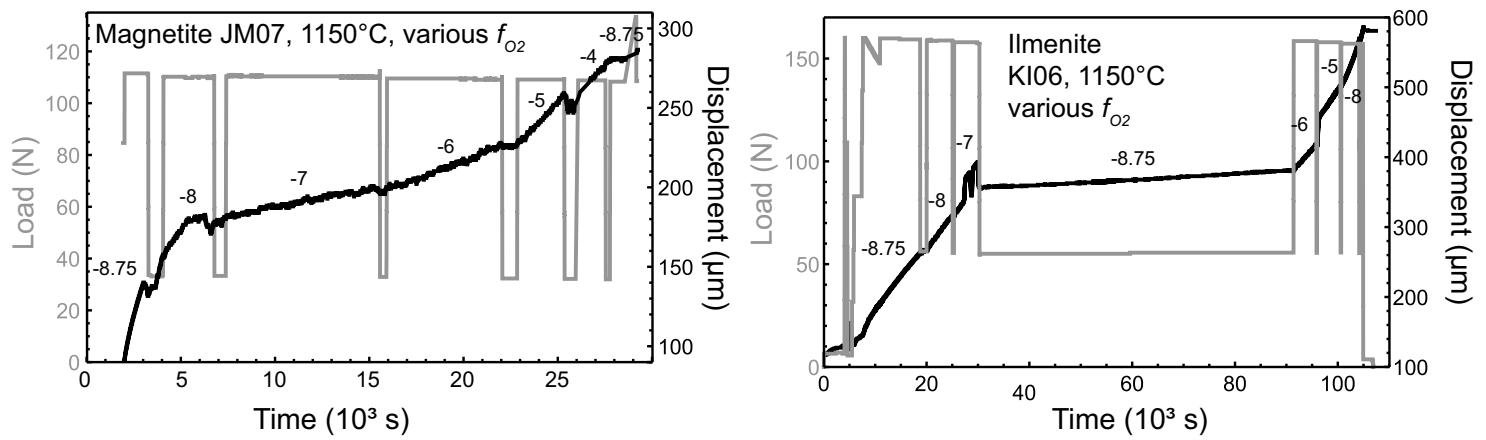

Fig. 2 Representative mechanical data from creep experiments on a magnetite and $\mathbf{b}$ ilmenite single crystals. Dashed lines for experiment KI05 represent creep segments for the repeated temperature step at $1100{ }^{\circ} \mathrm{C}$. Creep segments in (b) are labeled with oxygen fugacities in log atm units

\section{Creep of ilmenite single crystals}

Steady-state creep rates of samples deformed perpendicular, parallel, and at $45^{\circ}$ to the $<\mathrm{c}>$ axis ranged between $7.9 \times 10^{-8}$ and $3.0 \times 10^{-4} \mathrm{~s}^{-1}$ at applied stresses of $8.7-113$ MPa (Table 2). Compared to compression parallel and normal to $<0001>$, samples oriented at $45^{\circ}$ to the c-axis deformed at rates approximately 3 orders of magnitude faster (Fig. 6). Deduced stress exponents ranged between 2.9 and 5.8 (mean $3.8 \pm 0.6$ ), with average values of 4.3 $\pm 0.4,3.3 \pm 0.5$, and $3.9 \pm 0.4$, for creep perpendicular, parallel, and inclined to $<0001>$, respectively. Note that in experiment $\mathrm{KI} 03$, deformation below $1000^{\circ} \mathrm{C}$ was characterized by larger stress exponents than at higher temperatures, suggesting that the dominant mode of dislocation motion transitioned from climb to glide during that experiment. Experiment KI04 also displays a slight increase in stress exponent with decreasing temperature, possibly also reflecting an increasing contribution of dislocation glide. If only data above $990^{\circ}$ are considered, the stress exponents are the same for all ilmenite orientations within uncertainties. The activation energies for creep perpendicular, parallel, and inclined to $<0001>$ are $345 \pm 30,420 \pm 35$, and $360 \pm$ $40 \mathrm{~kJ} / \mathrm{mol}$ (Fig. 7). The uncertainties on $Q$ values overlap among the different orientations, and also overlap within error with the activation energy of $307 \pm 26 \mathrm{~kJ} / \mathrm{mol}$ reported for synthetic ilmenite aggregates by Dygert et al. (2016), also shown in Fig. 7. We determined pre-exponential factors 
(a)
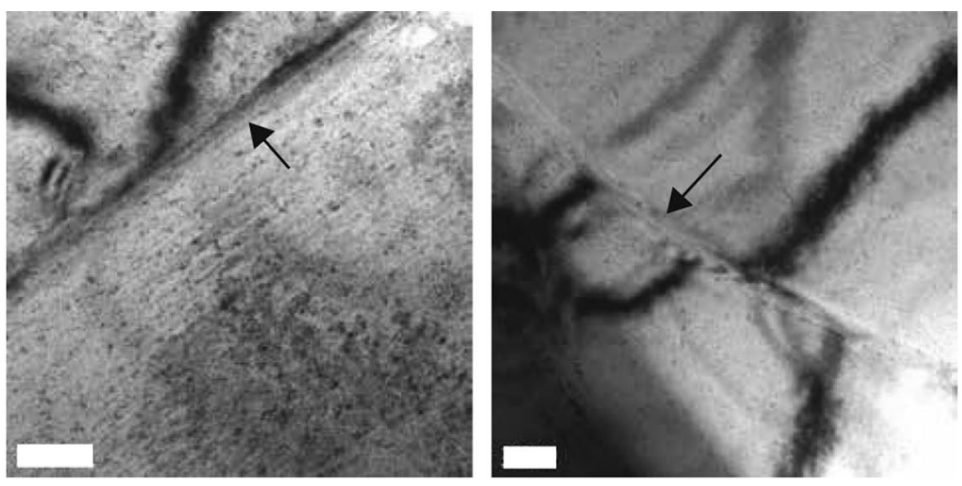

(b)
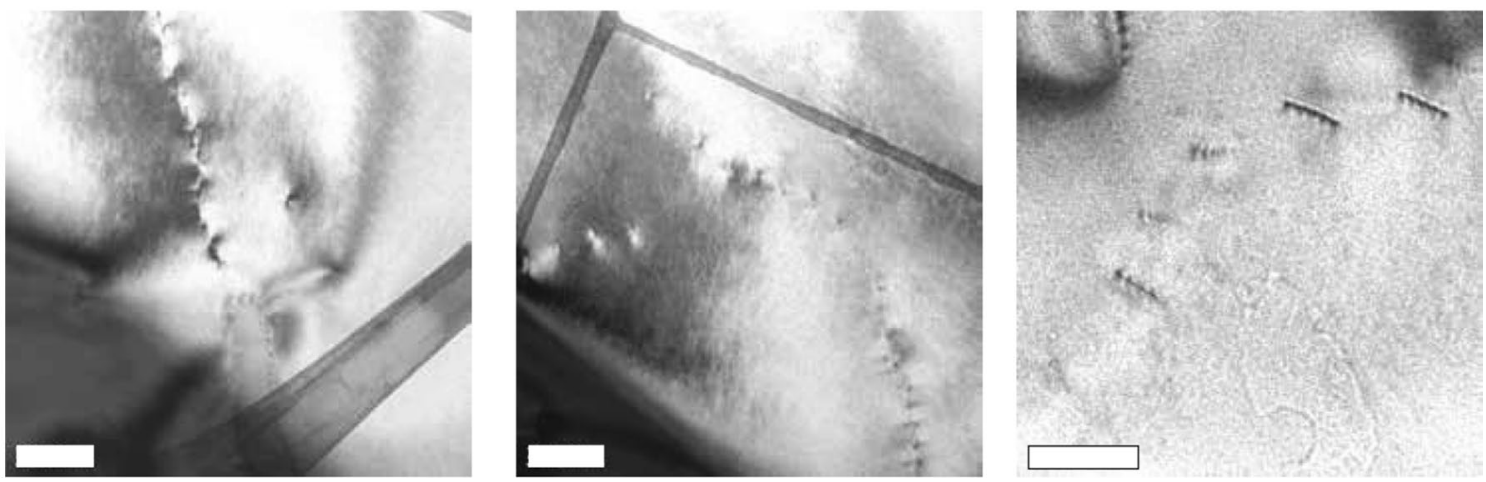

Fig. 3 Transmission election microscope images of crystalline defects in magnetite and ilmenite. a Slip bands (arrows) in magnetite singlecrystal sample JM06 compressed parallel to $<100>$; b dislocations

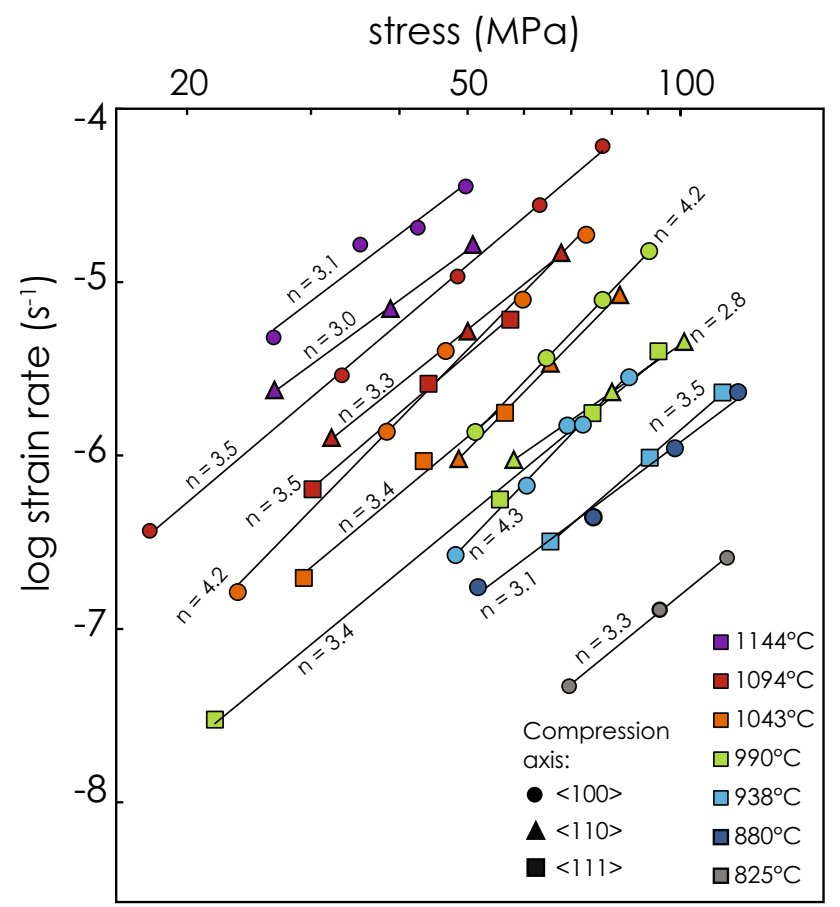

Fig. 4 Log-log plot of strain rate vs. differential stress results for magnetite single-crystal creep experiments at various temperatures. Stress exponents are indicated for each temperature step aligned into subgrain boundaries in ilmenite sample KI03 compressed at approximately $45^{\circ}$ to the basal plane. Scale bar in each figure represents $200 \mathrm{~nm}$

of $A=1.58,1.56 \times 10^{4}$, and $1.18 \times 10^{4}$ for compression directions perpendicular, parallel, and inclined to $<0001>$, respectively.

Compression parallel to the basal plane (normal to the c-axis) in experiment KI05 was distinguished from the other compression directions by a significant amount of hardening in the beginning of the experiment. Steady-state creep was reached after approximately $0.9 \%$ strain. Several creep steps at $1100^{\circ} \mathrm{C}$ were repeated at the end of the experiment and strain rates were considerably faster in these later segments than in the initial $1100^{\circ} \mathrm{C}$ steps (Table 2, open symbols in Fig. 6). This sample softening is attributed to the accumulation of small rotations in the crystal lattice that enabled activation of the easy basal slip plane. During experiment $\mathrm{KI03}$, two load steps were performed at $900^{\circ} \mathrm{C}$ before the sample failed. These data were not incorporated into the determinations of activation energy or mean stress exponent for compression at an angle to the $<\mathrm{c}>$ axis.

\section{Oxygen fugacity dependence of creep}

Results of magnetite creep tests at $1100^{\circ} \mathrm{C}$ and $1150^{\circ} \mathrm{C}$ with variable $f_{O_{2}}$ (compressed along $<111>$ ) are shown in Fig. 8 a. In the lower region of the investigated $f_{\mathrm{O} 2}$ range, 


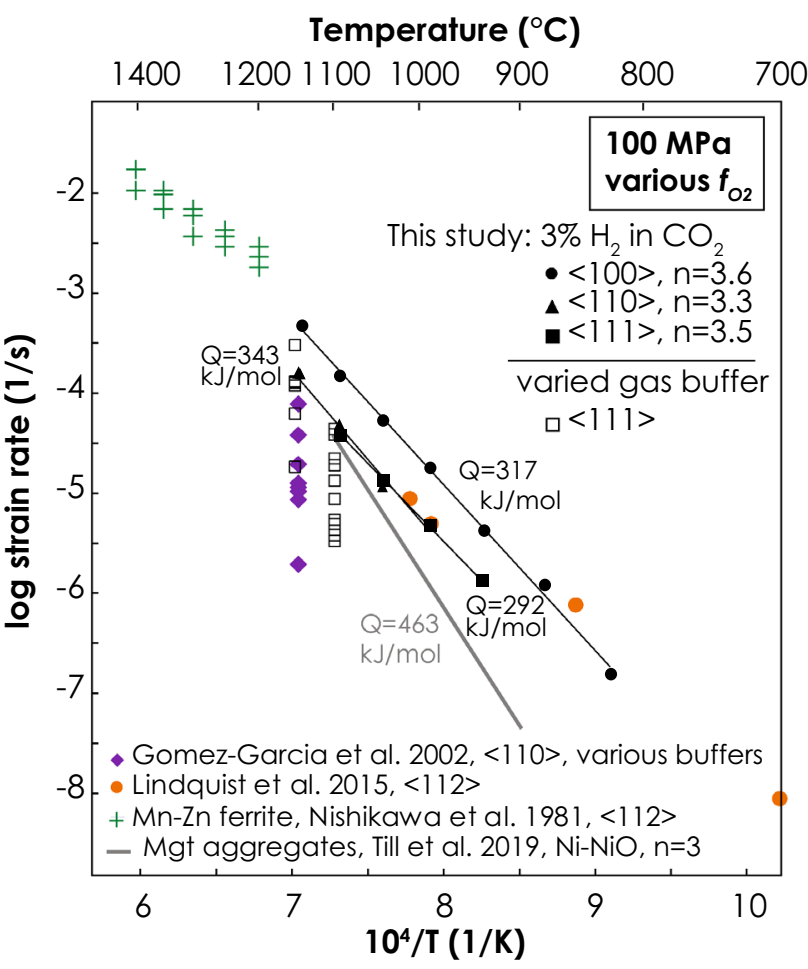

Fig. 5 Arrhenius plot of magnetite single-crystal creep data from this study normalized to a stress of $100 \mathrm{MPa}$ compared with polycrystalline magnetite dislocation creep flow laws from Till et al. (2019). These data sets are labeled with apparent activation energies without accounting for the oxygen fugacity dependence. Previous experimental creep data for single crystals of magnetite and other spinel oxides are also included. Data from experiment JM07 and from GómezGarcia et al. (2002) were obtained at various oxygen fugacity buffers, while the other data represent constant $f_{\mathrm{O}_{2}}$ buffers but various absolute $f_{\mathrm{O}_{2}}$ values magnetite strain rates decreased strongly with increasing $f_{\mathrm{O}_{2}}$ and reached a local minimum at approximately $2 \log$ units above the QFM buffer (approximately $10^{-8}$ and $10^{-7}$ atm at 1100 and $1150^{\circ} \mathrm{C}$, respectively). Above $\mathrm{QFM}+2$, strain rates exhibited a weaker but pronounced positive $f_{\mathrm{O}_{2}}$-dependence up to approximately $\mathrm{QFM}+4 \log$ units, above which value the creep rates were insensitive to further changes in $f_{\mathrm{O} 2}$. The mean oxygen fugacity exponents are $-0.7 \pm 0.3$ and 0.4 \pm 0.2 at $f_{O 2}$ ranges below and above $\mathrm{QFM}+2$, respectively.

Ilmenite was deformed at $1150^{\circ} \mathrm{C}$ with varying $f_{O 2}$ in experiment KI06 (Fig. 8b). In contrast to magnetite, ilmenite creep rates were essentially independent of oxygen fugacity. Above an $f_{\mathrm{O}_{2}}$ of approximately $3 \mathrm{log}$ units above the QFM buffer, ilmenite creep exhibited an irreversible increase in strain rates with both increasing and decreasing oxygen fugacity (Figs. 2, 8b), which reflects softening due to oxidative alteration. As pure end member ilmenite contains only ferrous iron, its $f_{\mathrm{O} 2}$ stability field does not extend as high as magnetite or titanohematite. Because this experiment does not represent steady-state deformation, data from experiment KI06 were not used to determine flow law parameters for ilmenite. Early ilmenite creep tests in this study were performed in an atmosphere of pure $\mathrm{CO}_{2}$, which exhibited similar creep rates for compression along different crystallographic axes, contrary to the expected behavior for hexagonal materials. Microstructural examination of these test samples confirmed that they had reacted to form a two-phase intergrowth during the experiments.

To derive a flow law for magnetite single crystals incorporating the effect of oxygen fugacity, we calculated strain rates for fixed values of stress, $n$, and $f_{O 2}$, as shown in Fig. 11a for representative oxygen fugacities of $10^{-10}$ and $10^{-6.5} \mathrm{~atm}$. Using these values, we estimated $f_{O 2^{-}}$independent activation energies of $715 \pm 150,725 \pm 145$, and 690
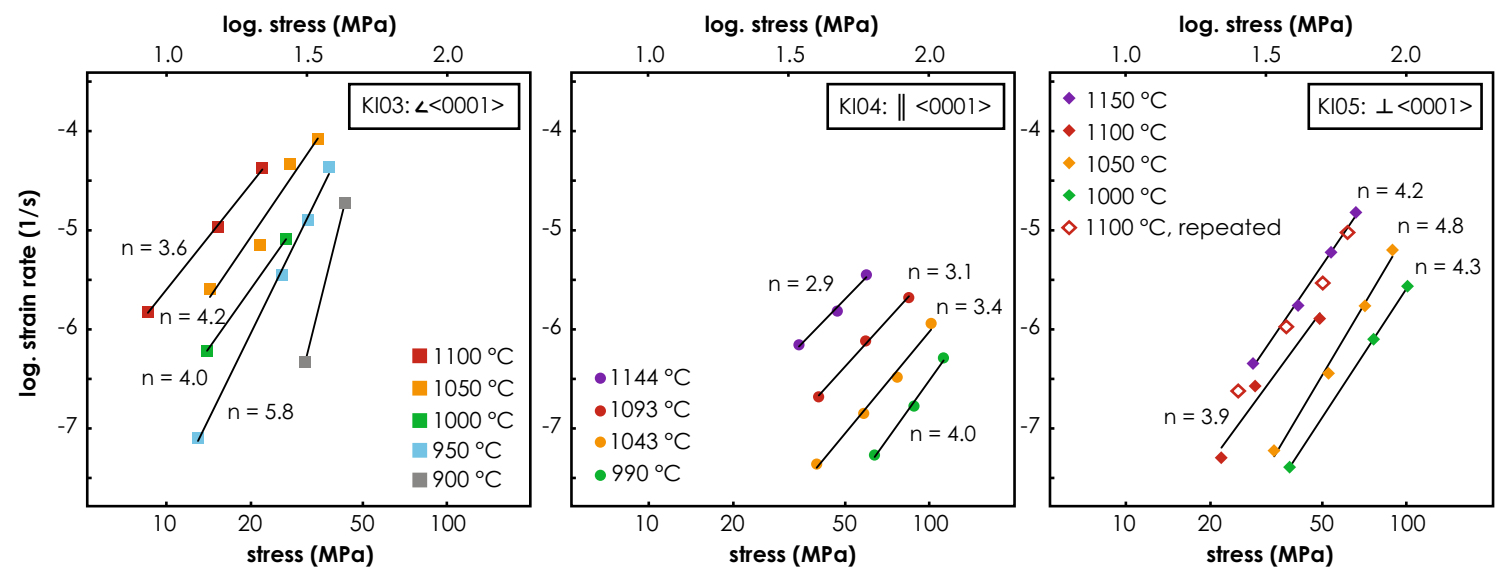

Fig. 6 Log-log plot of strain rate vs. differential stress for ilmenite single-crystal creep experiment results at various temperatures. Stress exponents are indicated for each temperature step. 


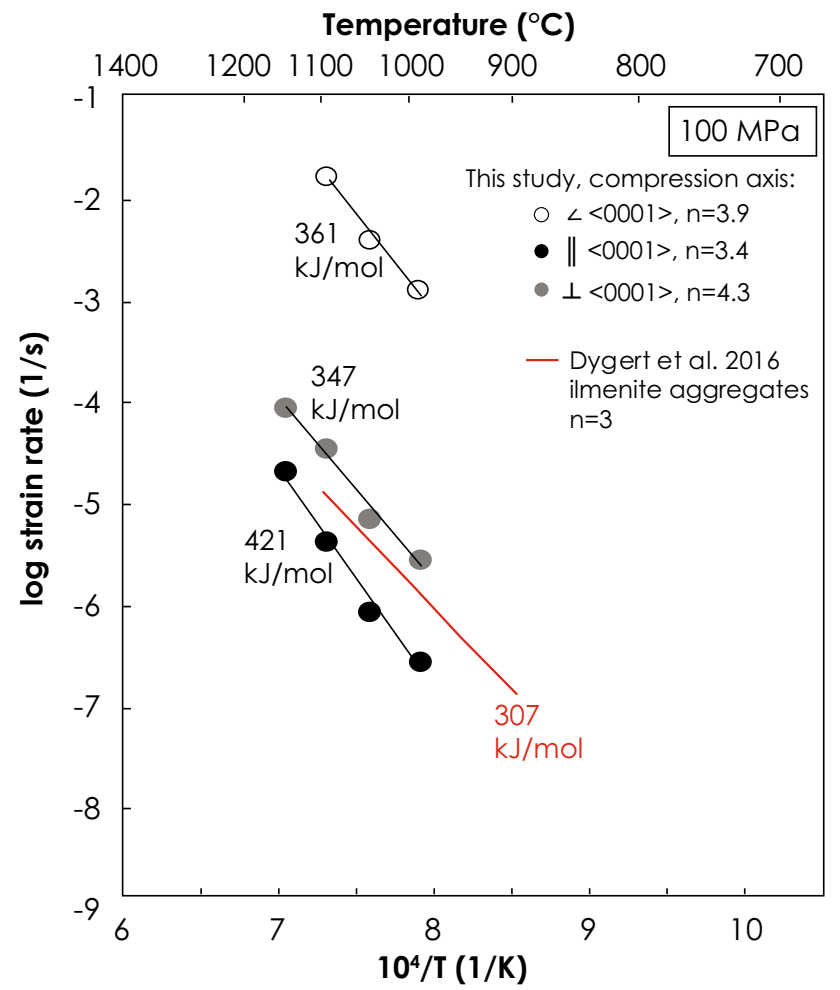

Fig. 7 Arrhenius plot of ilmenite single-crystal creep data from this study normalized to a stress of $100 \mathrm{MPa}$. Activation energies are indicated for each experiment. The dislocation creep flow law for synthetic ilmenite aggregates from Dygert et al. (2016) is shown for comparison

$\pm 150 \mathrm{~kJ} / \mathrm{mol}$ for $<100>,<110>$, and $<111>$ orientations, respectively, in the region of negative $f_{O_{2}}$-dependence below approximately QFM $+2 \log$ units. In the region of positive $f_{O 2}$-dependence, we estimated an activation energy of 185 \pm 100 for compression along $<111>$; however, this value should be regarded as only a rough approximation due to the difficulty of extrapolating the experimental data from the negative $f_{O_{2}}$-dependence regime to the positive-dependence regime. The uncertainties in the activation energies at fixed $f_{\mathrm{O}_{2}}$ are based on the uncertainties in the $f_{\mathrm{O} 2}$ exponents determined in experiment JM07. Flow law parameters for ilmenite and $f_{\mathrm{O}_{2}}$-dependent flow law parameters for magnetite are listed in Table 3 for each compression direction investigated in this study.

\section{Discussion}

\section{Effect of loading direction and comparison to creep of polycrystalline material}

The orientation dependence of magnetite single-crystal creep observed here is consistent with the flow anisotropy
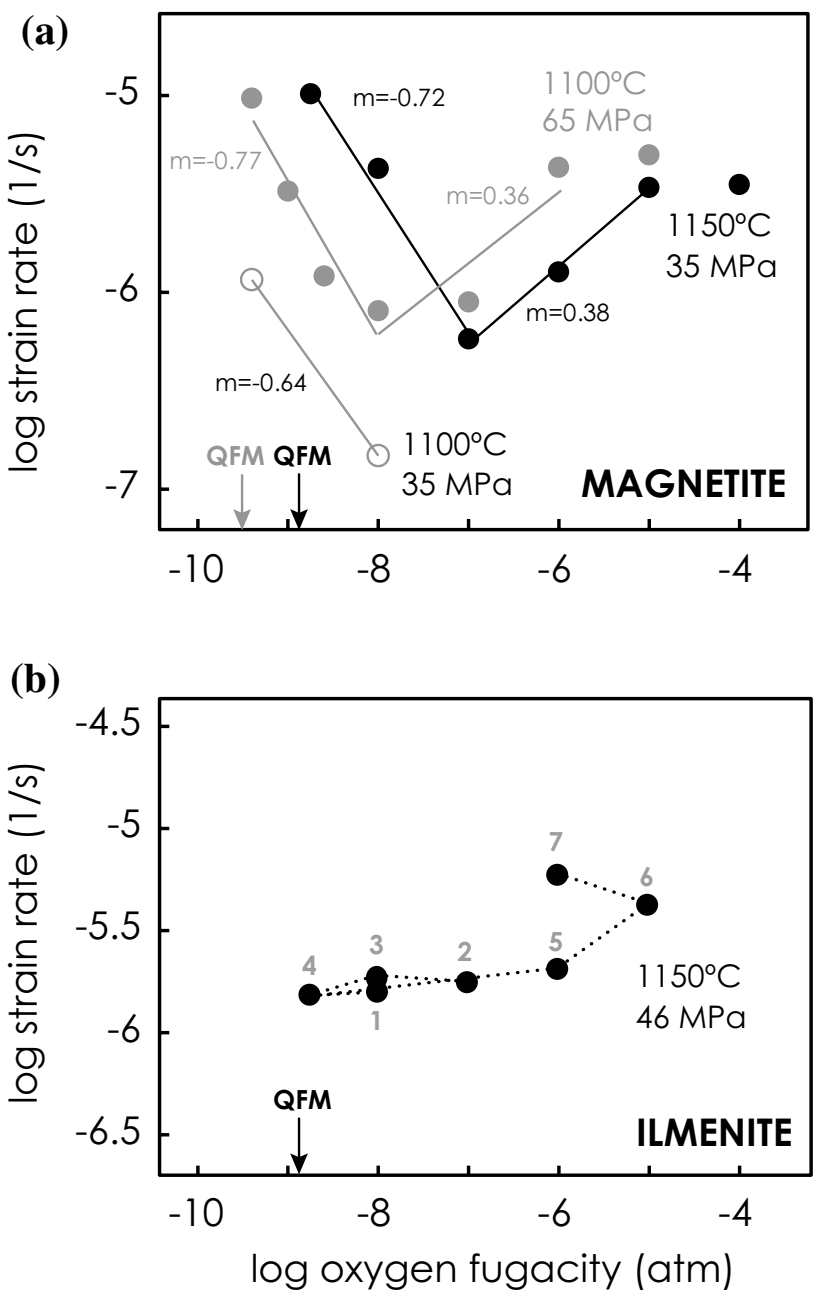

Fig. 8 Dependence of oxide single-crystal creep rates on oxygen fugacity for a magnetite compressed along $<111>$ at various temperatures and compressive stresses, and $\mathbf{b}$ ilmenite compressed normal to $<0001>$. Grey and black arrows indicate the oxygen fugacity of the QFM buffer at 1100 and $1150^{\circ}$, respectively. Solid lines in a are fits to parts of the data set representing regions of negative and positive creep dependence on $f_{O_{O}}$. Numbers next to each data point in $\mathbf{b}$ indicate the order of the creep steps

observed for natural magnetite crystals deformed at $400^{\circ} \mathrm{C}$ by Hennig-Michaeli and Siemes (1982). They noted that while magnetite was weaker in compression along $<100>$ than along $<110>$ or $<110>$ at $400^{\circ} \mathrm{C}$, the flow anisotropy was not distinct at $200^{\circ} \mathrm{C}$. Mn- $\mathrm{Zn}$ ferrite is an inverse spinelstructured oxide that forms a solid solution with magnetite, and is thus a good analog material for mechanical properties comparison. Similar anisotropy to that of magnetite was found in $\mathrm{Mn}-\mathrm{Zn}$ ferrite single crystals in experiments by Nishikawa et al. (1981a) as cited in Okamoto (1989), in agreement with our observations for magnetite (Fig. 4). Their data for compression along $<112>$ are shown in Fig. 5, which have creep rates comparable to those of magnetite measured in this study when extrapolated to higher 
temperatures. However, Fig. 9 of Nishikawa et al. (1981a) indicates a strength difference of around $100 \mathrm{MPa}$ between the weak and strong directions in $\mathrm{Mn}-\mathrm{Zn}$ ferrite at $1100^{\circ} \mathrm{C}$, which is much higher than the strength difference we determined of approximately $20 \mathrm{MPa}$ (Fig. 4) for magnetite at a given strain rate (Fig. 4). Although Lindquist et al. (2015) did not determine stress exponents in their creep experiments on magnetite single crystals, we normalized their data to $100 \mathrm{MPa}$ assuming a stress exponent of 3 , which is shown in Fig. 5. Their microstructural observations indicated that compression along $\langle 112\rangle$ resulted in dominant slip on $\{111\}$ planes, and their results agree well with those of this study despite the large uncertainties on their reported strain rates.

The results of our ilmenite experiments demonstrate highly anisotropic single-crystal creep, as found previously for other hexagonal phases. The strength of polycrystalline hexagonal minerals is typically close to that of the hardest slip system in single crystals (Hutchinson 1977). The strength of polycrystalline olivine, which is orthorhombic, appears to be intermediate between the weak and hard slip systems in olivine based on a comparison of experimental creep data for polycrystalline dunite and olivine single crystals by Keefner et al. (2011). The dislocation creep law for polycrystalline ilmenite by Dygert et al. (2016) shown in Fig. 7 is therefore in excellent agreement with our ilmenite single crystal results, plotting close to the strain rates for compression in the hard directions parallel and perpendicular to the basal plane. Their activation energy of 307 is somewhat lower than our observed values, but is reasonably close considering the different sample sources and experimental apparatus used. It is also worth noting that the strength of magnetite aggregates studied by Till et al. (2019) is closest to those of the harder magnetite single-crystal orientations found in this study. Experimentally determined creep rates for polycrystalline hematite by Siemes et al. (2003) are comparable to our data for ilmenite compressed perpendicular to $\langle\mathrm{c}\rangle$ (experiment KI05) but with a lower activation energy of $225 \mathrm{~kJ} / \mathrm{mol}$.
Siemes et al. (2003) identified (c) $<\mathrm{a}>$ and $\{\mathrm{a}\}<\mathrm{m}>$ as the most important slip systems in hematite, which are likely the main slip systems activated in our ilmenite samples compressed at an angle to the basal plane. While basal slip is the most easily activated slip system in hexagonal crystals, samples compressed parallel to the $\langle\mathrm{c}\rangle$ axis and perpendicular to $\langle\mathrm{c}\rangle$ (parallel to the $<\mathrm{a}\rangle$ axis) have no resolved shear stress on the basal plane and thus cannot deform by basal slip. Ilmenite samples compressed parallel to the $<a>$ axis (experiment KI05) may deform by prismatic slip, $\{10 \overline{1}$ $0\}<11 \overline{2} 0\rangle$, and/or pyramidal slip, e.g., $\{10 \overline{1} 1\}<12 \overline{1} 0>$, while pyramidal slip is likely to be the main system activated in samples compressed along the $\langle\mathrm{c}\rangle$ axis (experiment KI04). The strain hardening observed early in experiment KI05 likely reflects deformation accommodated by twinning, as twinning in hexagonal titanium has been associated with strain hardening behavior (Salem et al. 2003). Siemes et al. (2008) observed evidence of r-twinning in hematite single crystals compressed both along the $<c>$ axis and along the $<a>$ axis, so twinning may be an important deformation mechanism in the initial stages of ilmenite deformation when the crystals are not favorably oriented for basal slip.

\section{Effect of oxygen fugacity on dislocation creep rates in magnetite}

The activation energies determined here for magnetite single crystals are notably lower than that reported for dislocation creep of dry polycrystalline magnetite by Till et al. (2019) of $463 \pm 19 \mathrm{~kJ} / \mathrm{mol}$. The discrepancy partly arises from the different oxygen fugacity buffers imposed by the $\mathrm{Ni}-\mathrm{NiO}$ jacket used in the Paterson rig by Till et al. (2019) and the $\mathrm{CO}_{2}-\mathrm{H}_{2}$ mixture used in the creep rig here. When both sets of data are plotted at the experimental buffers, creep rates are similar at high temperatures but differ significantly at low temperature (Fig. 5). Figure 9a illustrates that the difference in $f_{\mathrm{O}_{2}}$ between the two buffers is also greater at lower temperatures. Although this difference is relatively small, the high sensitivity of magnetite creep to $f_{\mathrm{O}_{2}}$ strongly influences the apparent activation energy. Using the $f_{O_{2}}$ dependence
Table 3 Flow law parameters for creep of magnetite and ilmenite single crystals of the form $\dot{\epsilon}=A \sigma^{n} f_{O_{2}}^{r} \exp \{-Q / R T\}$

\begin{tabular}{lllll}
\hline Material and compression direction & $n$ & $r$ & $Q \mathrm{~kJ} / \mathrm{mol}$ & $\log A \mathrm{MPa}^{-n} \mathrm{~atm}^{-r} \mathrm{~s}^{-1}$ \\
\hline $\begin{array}{l}\text { positive } f_{\mathrm{O}_{2}} \text {-dependent regime } \\
\text { Magnetite, }<111>\end{array}$ & $3.5 \pm 0.4$ & $0.4 \pm 0.2$ & $185 \pm 100$ & $3.5 \times 10^{-3}$ \\
negative $f_{O_{2}}$-dependent regime & & & & \\
Magnetite, $<100>$ & $3.6 \pm 0.5$ & $-0.7 \pm 0.2$ & $715 \pm 150$ & $5.5 \times 10^{9}$ \\
Magnetite, $<110>$ & $3.3 \pm 0.6$ & $-0.7 \pm 0.2$ & $725 \pm 145$ & $1.6 \times 10^{10}$ \\
Magnetite, $<111>$ & $3.5 \pm 0.4$ & $-0.7 \pm 0.2$ & $690 \pm 150$ & $2.5 \times 10^{8}$ \\
Ilmenite, $<\mathrm{a}>$ & $4.3 \pm 0.4$ & 0 & $345 \pm 30$ & 1.58 \\
Ilmenite, $<\mathrm{c}>$ & $3.3 \pm 0.5$ & 0 & $420 \pm 35$ & $1.6 \times 10^{4}$ \\
Ilmenite, oblique to $<\mathrm{c}>$ and $<\mathrm{a}>$ & $3.9 \pm 0.4$ & 0 & $360 \pm 40$ & $1.2 \times 10^{4}$ \\
\hline
\end{tabular}




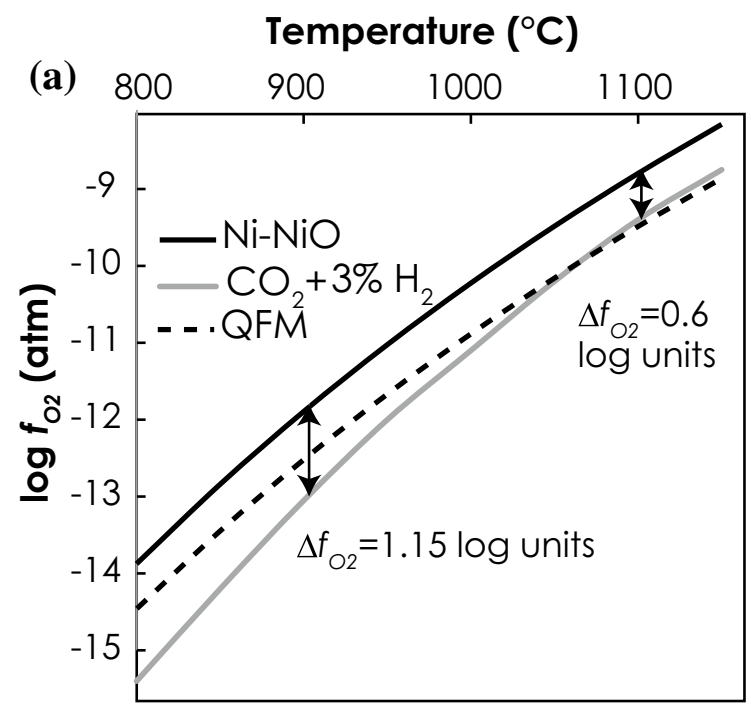

Fig. 9 a Oxygen fugacity curves vs. temperature for different buffers used in magnetite deformation experiments. Values for quartzfayalite-magnetite (QFM) and $\mathrm{Ni}-\mathrm{NiO}$ are from Myers and Eugster (1983) and Huebner and Sato (1970), respectively, and oxygen fugacity values for the $\mathrm{CO}_{2}-\mathrm{H}_{2}$ gas mixture are from Prunier and Hewitt

determined in experiment JM07 (Fig. 8a), we adjusted the normalized creep rates from experiment JM04 to oxygen fugacities at the $\mathrm{Ni}-\mathrm{NiO}$ buffer for comparison to the data of Till et al. (2019), as shown as Fig. 9b. The resulting singlecrystal creep rates come into much closer agreement with the aggregates with apparent activation energies of $370 \pm$ $20,390 \pm 20$, and $350 \pm 25 \mathrm{~kJ} / \mathrm{mol}$ for $\langle 100\rangle,\langle 110\rangle$, and $<111>$ orientations, respectively, with uncertainties based on those of the $f_{\mathrm{O}_{2}}$ exponents determined from experiment JM07.

A summary of reported activation energies for oxygen diffusion in magnetite and other spinel-structured oxide phases is shown in Fig. 10. Only two studies have directly measured $\mathrm{O}$ diffusion in magnetite, and it should be noted that both were performed in the presence of hydrous species. Giletti and Hess (1988) reported an activation energy of 188 $\mathrm{kJ} / \mathrm{mol}$ and suggested a change in the diffusion mechanism below $500^{\circ} \mathrm{C}$, at which point the low-temperature activation energy of $71 \mathrm{~kJ} / \mathrm{mol}$ determined by Castle and Surman (1967) may be more relevant. Crouch and Robertson (1990) inferred an activation energy of $264 \mathrm{~kJ} / \mathrm{mol}$ for oxygen diffusion in magnetite based on creep experiments in a bending apparatus. The activation energies for $\mathrm{O}$ diffusion in $\mathrm{Ni}-\mathrm{Cr}$ spinel and Ni-ferrite from Kingery et al. (1960) and O'Bryan and DiMarcello (1970) of 295 and $255 \mathrm{~kJ} / \mathrm{mol}$, respectively, are broadly similar to the apparent activation energies of magnetite found in this study. Reported Fe diffusivities in
Temperature $\left({ }^{\circ} \mathrm{C}\right)$

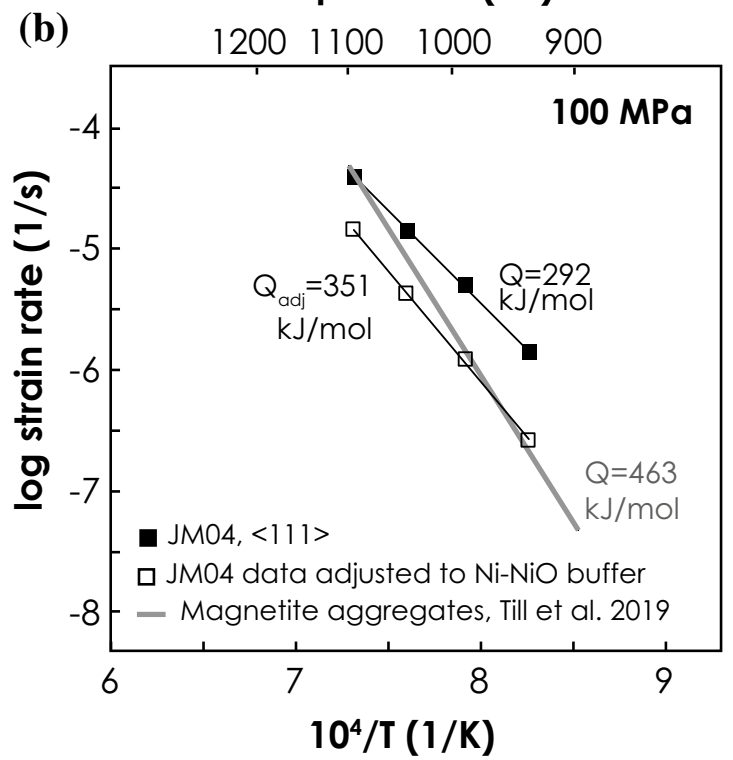

(1981). b Temperature dependence of magnetite creep rates from experiment JM04 before and after adjusting to oxygen fugacities at the $\mathrm{Ni}-\mathrm{NiO}$ buffer compared with the polycrystalline magnetite flow law of Till et al. (2019). The apparent activation energies are indicated for each data set

magnetite from Dieckmann and Schmalzried (1977), also shown in Fig. 10, are at least four to five orders of magnitude faster than $\mathrm{O}$ diffusion, so oxygen should be the rate-limiting species for creep.

A strong $f_{O 2}$ dependence for creep in magnetite single crystals was previously reported by Gómez-Garcia et al. (2002). Although they mainly reported relative changes in strain rate, they also found a transition from negative to positive $f_{\mathrm{O}_{2}}$ dependence with average $f_{\mathrm{O}_{2}}$ exponents around -0.4 and 0.35 . Similarly, both iron and oxygen diffusion have been demonstrated to vary nonlinearly with $f_{\mathrm{O}_{2}}$ (see review by Van Orman and Crispin (2010)). Diffusion of $\mathrm{Fe}, \mathrm{Ti}$, and many other trace element cations in magnetite are well described by a V-shaped trend (Dieckmann and Schmalzried 1977; Sievwright et al. 2020) that transitions from $f_{O_{2}}^{-2 / 3}$ to $f_{O_{2}}^{2 / 3}$. This pattern of cation diffusivities is typically assumed to represent a change in diffusion mechanism from iron interstitials to iron vacancies with increasing $f_{\mathrm{O}_{2}}$ based on the point defect reactions. For oxygen diffusion by a vacancy mechanism, diffusion rates are expected to vary as $f_{O_{2}}^{-1 / 2}$, which is supported by oxygen diffusivities in magnetite reported by Millot and Niu (1997) and Millot et al. (1997) proportional to $f_{O_{2}}^{-1 / 2}$ and $f_{O_{2}}^{1 / 6}$. Oxygen diffusion data from Millot and Niu (1997) at different $f_{O_{2}}$ buffers and a single temperature are shown in Fig. 10 for comparison. They interpreted the positive $f_{\mathrm{O}_{2}}$ dependence at more oxidizing conditions as an effect of coupled iron 
and oxygen vacancy clusters. Positive correlations between oxygen diffusion and $f_{\mathrm{O}_{2}}$ have also been observed in oxides such as Ni-ferrite (O'Bryan and DiMarcello 1970), spinel (Reddy and Cooper 1981), and olivine (Ryerson and McKeegan 1994). These studies all concluded that O diffusion could not operate by an oxygen vacancy mechanism, but suggested the possibility of a covacancy mechanism as described by Moore et al. (1958), whereby iron vacancies facilitate oxygen diffusion. $\mathrm{O}$ diffusion by $\mathrm{O}$ interstitials is also consistent with a positive $f_{\mathrm{O}_{2}}$ dependence, but is generally considered unlikely due to the large anion size. Our determined $f_{\mathrm{O}_{2}}$ exponent of -0.7 and 0.4 are consistent with deformation rates controlled by $\mathrm{O}$ diffusion by a vacancy mechanism at lower $f_{\mathrm{O}_{2}}$ values, while the regime of positive $f_{\mathrm{O}_{2}}$-dependence likely represents creep limited by diffusion of oxygen and iron vacancy pairs.

\section{Relative strengths of Fe-Ti oxides}

Figure $11 \mathrm{~b}$ displays normalized ilmenite creep rates in hard orientations along with magnetite creep rates for the $<111>$ orientation from this study extrapolated to various oxygen fugacity buffers based on the $f_{\mathrm{O}_{2}}$-dependence determined in experiment JM07. Dislocation creep flow laws for polycrystalline hematite (Siemes et al. 2003) and ilmenite (Dygert et al. 2016) are also shown for comparison. Magnetite and ilmenite often occur together in oxide-rich zones of highly

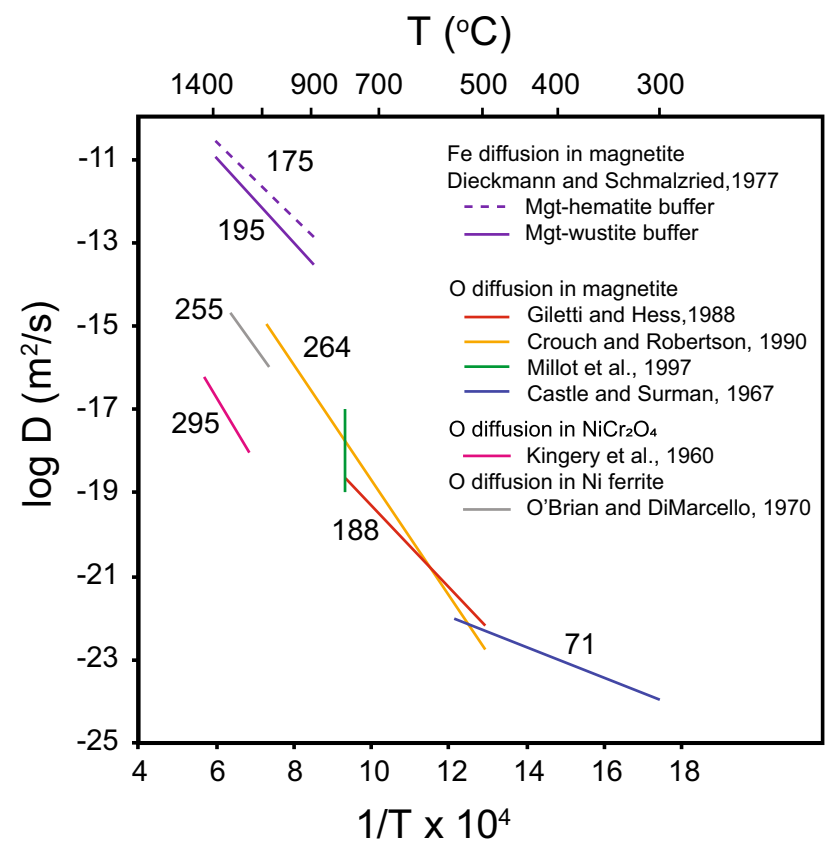

Fig. 10 Arrhenius plot of reported $\mathrm{Fe}$ and $\mathrm{O}$ diffusivities in magnetite and experimental data for $\mathrm{O}$ diffusion in other spinel-structured oxides. Labels for each data set represent activation energies in $\mathrm{kJ} /$ mol differentiated igneous rocks (Ashwal 1982), while magnetite and hematite may occur together in banded iron formations where fluid-present deformation facilitates oxidative transformation of magnetite to secondary hematite (Lagoeiro 1998). At oxidizing conditions near the magnetite-hematite $(\mathrm{MH})$ buffer, magnetite is predicted to be moderately stronger than hematite. However, it is worth noting that Crouch (1972) determined an oxygen fugacity exponent of -0.14 for diffusion creep of hematite, which could further influence the relative strengths of hematite and magnetite. At more reducing conditions where ilmenite is stable, magnetite is expected to be slightly weaker than ilmenite at the QFM buffer, but stronger than ilmenite at QFM + $2 \log$ units. In deformation experiments on magnetite crystals with ilmenite inclusions, Hennig-Michaeli and Siemes (1982) described the ilmenite regions as being more highly strained than the magnetite, indicating ilmenite to be the weaker phase at their experimental conditions.

The majority of experiments on magnetite aggregates by Till et al. (2019) were conducted under dry conditions. However, they did perform one experiment under hydrous conditions, which indicated that magnetite creep rates are significantly enhanced in the presence of trace amounts of water. Thus, in addition to being highly sensitive to oxygen fugacity, magnetite creep likely depends strongly on the presence of hydrous species, which will influence the oxygen fugacity buffer conditions as well as point defect concentrations. Small variations in trace water contents could further account for the differences between the dislocation creep flow laws presented here and the nominally dry triaxial experiments of Till et al. (2019), as water fugacity will always be lower in the absence of confining pressure. The effect of hydrous conditions on deformation rates in $\mathrm{Fe}-\mathrm{Ti}$ oxide minerals remains to be explored in detail and is a factor that will affect the nature of strain partitioning among oxides and between oxide and silicate phases.

While $\{111\}$ planes are generally held to be the dominant slip plane in magnetite (Hornstra 1960), the similar strengths of the three magnetite orientations found in this study demonstrate that other slip planes ( $\{110\}$ and $\{100\})$ may be activated relatively easily. In contrast, we found large strength differences for the various ilmenite orientations, reflecting the difficulty of activating slip on planes other than (0001). These contrasting behaviors may partially explain why microstructural studies of deformed $\mathrm{Fe}-\mathrm{Ti}$ oxides often find strong crystallographic textures in ilmenite and weak or no crystallographic preferred orientation in co-existing magnetite (Agar and Lloyd 1997; Terry and Heidelbach 2006; Kontny et al. 2012). Similar differences in texture development have also been noted between cubic and hexagonal metals (Wang and Huang 2003), where hexagonal materials have greater mechanical anisotropy and potential for 


\section{(a)}

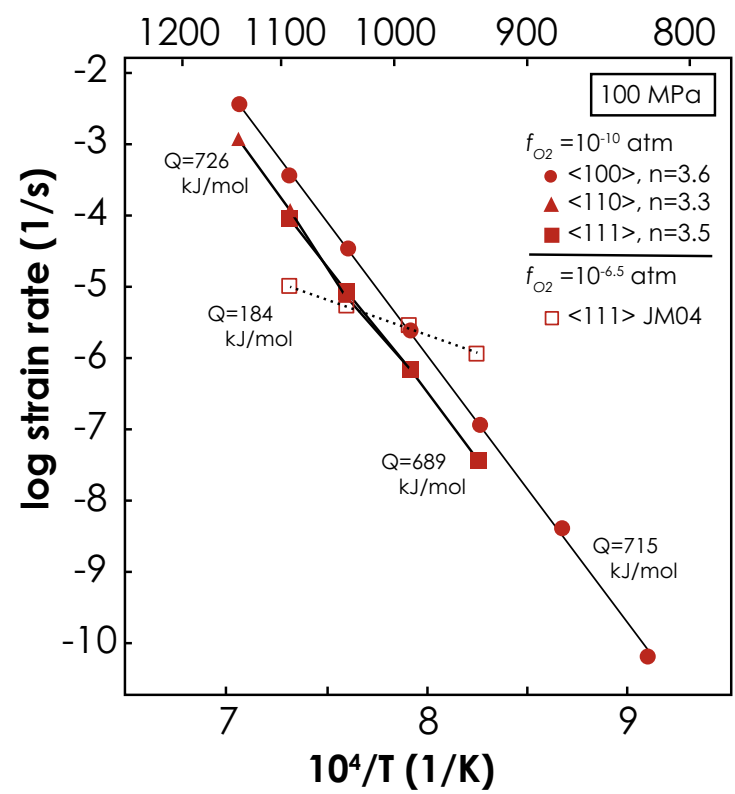

Fig. 11 a Arrhenius plot of magnetite single-crystal creep rates at constant oxygen fugacities. b Plot comparing creep rates for ilmenite compressed along hard orientations with predicted creep rates for magnetite at the quartz-fayalite-magnetite (QFM) buffer, 2 log units

texture development due to having fewer easy slip systems than cubic crystals.

\section{Conclusions}

The creep behavior of natural magnetite and ilmenite single crystals was investigated as a function of temperature, orientation, and oxygen fugacity. Ilmenite single crystals exhibit high mechanical anisotropy and are weakest in an orientation that facilitates easy slip on basal planes. In contrast, magnetite creep rates have low dependence on loading direction, being slightly weaker in compression along $<100>$ than along $<110>$ or $<111>$. Ilmenite single-crystal creep rates in hard directions are in excellent agreement with published flow laws for synthetic aggregates. Magnetite single crystals appear to be slightly weaker than polycrystalline magnetite studied in earlier work and our observed activation energies are also lower. This apparent discrepancy results at least partially from the strong $f_{\mathrm{O}_{2}}$-dependence in magnetite: after correcting for the different $f_{\mathrm{O}_{2}}$ buffers used in the previous experiments, magnetite single-crystal creep strength comes into closer agreement with polycrystalline magnetite data. Magnetite strength relative to other Fe-Ti oxides and silicate minerals thus depends strongly on oxygen fugacity as well.

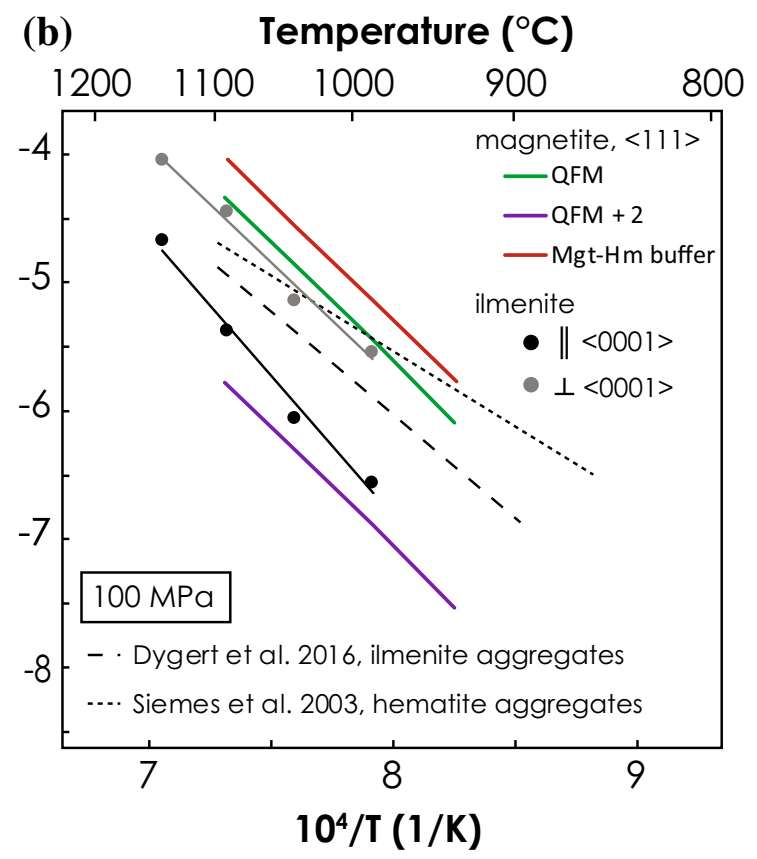

above the QFM buffer, and the magnetite-hematite buffer. Data for ilmenite compressed oblique to $\langle c\rangle$ falls outside the limit of the scale in this figure. Flow laws for ilmenite and hematite aggregates from Dygert et al. (2016) and Siemes et al. (2003) are also shown

Acknowledgements We are grateful to Michael Naumann for technical assistance and support. The Alexander von Humboldt Foundation is thanked for supporting this research through a fellowship to JLT. We also thank Dieter Rhede for help with electron microprobe analysis and Richard Wirth and Anja Schreiber for help with TEM sample preparation and analysis. We appreciate constructive review comments by Lars Hansen and an anonymous reviewer.

Funding Open Access funding enabled and organized by Projekt DEAL.

\section{Compliance with ethical standards}

Conflict of interest The authors declare that they have no conflict of interest.

Open Access This article is licensed under a Creative Commons Attribution 4.0 International License, which permits use, sharing, adaptation, distribution and reproduction in any medium or format, as long as you give appropriate credit to the original author(s) and the source, provide a link to the Creative Commons licence, and indicate if changes were made. The images or other third party material in this article are included in the article's Creative Commons licence, unless indicated otherwise in a credit line to the material. If material is not included in the article's Creative Commons licence and your intended use is not permitted by statutory regulation or exceeds the permitted use, you will need to obtain permission directly from the copyright holder. To view a copy of this licence, visit http://creativecommons.org/licenses/by/4.0/. 


\section{References}

Agar S, Lloyd G (1997) Deformation of Fe-Ti oxides in gabbroic shear zones from the Mark area. In: Karson J, Cannat M, Miller D, Elthon D (eds) Proceedings of the Ocean Drilling Program: Scientific Results, vol 153, pp 123-141

Andersen DJ, Lindsley DH (1988) Internally consistent solution models for Fe-Mg-Mn-Ti oxides. Fe-Ti oxides. Am Mineralogist 73(7-8):714-726

Ashwal LD (1982) Mineralogy of mafic and Fe-Ti oxide-rich differentiates of the Marcy anorthosite massif, Adirondacks. New York. Am Mineralogist 67(1-2):14-27

Broese Van Groenou A, Kadijk S (1989) Slip patterns made by sphere indentations on single crystal Mn-Zn ferrite. Acta Metall 37(10):2613-2624

Castle J, Surman P (1967) Self-diffusion of oxygen in magnetite: Techniques for sampling and isootopic analysis of micro quantities of water. J Phys Chem 71(13):4255-4259

Charlier B, Grove TL, Namur O, Holtz F (2018) Crystallization of the lunar magma ocean and the primordial mantle-crust differentiation of the moon. Geochim Cosmochim Acta 234:50-69

Charpentier P, Rabbe P, Manenc J (1968) Mise en evidence de la plasticite de la magnetite mesure de la durete en fonction de la temperature. Mater Res Bull 3(2):69-78

Crouch A (1972) High-temperature deformation of polycrystalline $\mathrm{Fe}_{2}$ $\mathrm{O}_{3}$. J Am Ceram Soc 55(11):558-563

Crouch A, Robertson J (1990) Creep and oxygen diffusion in magnetite. Acta Metall Mater 38(12):2567-2572. https://doi. org/10.1016/0956-7151(90)90268-L

Dick H, Natland J, Alt J, Bach W, Bideau D, Gee J, Haggas S, Hertogen J, Hirth G, Holm P et al (2000) A long in situ section of the lower ocean crust: results of ODP Leg 176 drilling at the Southwest Indian Ridge. Earth Planet Sci Lett 179(1):31-51

Dick H, MacLeod C, Blum P, Abe N, Blackman D, Bowles J, Cheadle M, Cho K, Ciaela J, Deans J, et al (2017) Expedition 360 summary. MacLeod, CJ, Dick, HJB, Blum, P, and the Expedition 360

Dieckmann R, Schmalzried H (1977) Defects and cation diffusion in magnetite (II). Berichte der Bunsengesellschaft für Physikalische Chemie 81(4):414-419

Duclos R, Doukhan N, Escaig B (1978) High temperature creep behaviour of nearly stoichiometric alumina spinel. J Mater Sci 13(8):1740-1748

Dygert N, Hirth G, Liang Y (2016) A flow law for ilmenite in dislocation creep: implications for lunar cumulate mantle overturn. Geophys Res Lett 43(2):532-540. https://doi.org/10.1002/2015G L066546

Freund D, Wang Z, Rybacki E, Dresen G (2004) High-temperature creep of synthetic calcite aggregates: influence of Mn content. Earth Planet Sci Lett 226(3):433-448

Giletti B, Hess K (1988) Oxygen diffusion in magnetite. Earth Planet Sci Lett 89(1):115-122

Gómez-Garcıa D, Domınguez-Rodriguez A, Castaing J, Millot F (2002) The influence of oxygen partial pressure on recovery creep in magnetite single crystals. J Phys Chem Solids 63(2):185-191

Groves G, Kelly A (1963) Independent slip systems in crystals. Phil Mag 8(89):877-887

Hennig-Michaeli C, Siemes H (1982) Compression experiments on natural magnetite crystals at $200^{\circ} \mathrm{C}$ and $400^{\circ} \mathrm{C}$ at $400 \mathrm{MPa}$ confining pressure. In: Issues in Rock Mechanics: Proceedings, Twenty-Third Symposium on Rock Mechanics, the University of California, Berkeley, California, August 25-27, Random House Trade, p 380

Hornstra J (1960) Dislocations, stacking faults and twins in the spinel structure. J Phys Chem Solids 15(3-4):311-323
Huebner JS, Sato M (1970) Oxygen fugacity-temperature relationships of manganese oxide and nickel oxide buffers. Am Mineral 55(5-6):934

Hutchinson J (1977) Creep and plasticity of hexagonal polycrystals as related to single crystal slip. Metall Trans A 8(9):1465-1469

Jt M, Eugster H (1983) The system Fe-Si-O: oxygen buffer calibrations to $1500 \mathrm{~K}$. Contrib Miner Petrol 82(1):75-90

Keefner J, Mackwell S, Kohlstedt D, Heidelbach F (2011) Dependence of dislocation creep of dunite on oxygen fugacity: implications for viscosity variations in Earth's mantle. J Geophys Res 116(B5)

Kingery W, Hill D, Nelson R (1960) Oxygen mobility in polycrystalline $\mathrm{NiCr}_{2} \mathrm{O}_{4}$ and $\alpha-\mathrm{Fe}_{2} \mathrm{O}_{3}$. J Am Ceram Soc 43:473-476

Kontny A, Engelmann R, Grimmer J, Greiling R, Hirt A (2012) Magnetic fabric development in a highly anisotropic magnetite-bearing ductile shear zone (Seve Nappe Complex, Scandinavian Caledonides). Int J Earth Sci 101(3):671-692

Lagoeiro L (1998) Transformation of magnetite to hematite and its influence on the dissolution of iron oxide minerals. J Metamorph Geol 16(3):415-423

Lindquist A, Feinberg JM, Harrison R, Loudon J, Newell A (2015) Domain wall pinning and dislocations: investigating magnetite deformed under conditions analogous to nature using transmission electron microscopy. J Geophys Res 120(3):1415-1430

Mackwell S, Dimos D, Kohlstedt D (1988) Transient creep of olivine: point-defect relaxation times. Philos Mag A 57(5):779-789

Mamtani MA, Reznik B, Kontny A (2020) Intracrystalline deformation and nanotectonic processes in magnetite from a naturally deformed rock. J Struct Geol 104045

McEnroe S, Harrison R, Robinson P, Langenhorst F (2002) Nanoscale haematite-ilmenite lamellae in massive ilmenite rock: an example of "lamellar magnetism" with implications for planetary magnetic anomalies. Geophys J Int 151(3):890-912

Millot F, Niu Y (1997) Diffusion of $\mathrm{O}^{18}$ in $\mathrm{Fe}_{3} \mathrm{O}_{4}$ : an experimental approach to study the behavior of minority defects in oxides. $\mathrm{J}$ Phys Chem Solids 58(1):63-72. https://doi.org/10.1016/S0022 -3697(96)00101-1

Millot F, Lorin J, Klossa B, Niu Y, Tarento J (1997) Oxygen self-diffusion in $\mathrm{Fe}_{3} \mathrm{O}_{4}$ : an experimental example of interactions between defects. Ber Bunsen-Ges 101(9):1351-1354

Mishra R, Thomas G (1976) Lattice defects in lithium ferrite spinel. In: Fulrath R, JA Pask J (eds) Ceramic Microstructures, 1976, with Emphasis on Energy Related Applications: Proceedings of the Sixth International Materials Symposium Ceramic Microstructures '76, Held at the University of California, Berkeley, August 24-27, 1976, vol 1, Westview Press

Moore WJ, Ebisuzaki Y, Sluss JA (1958) Exchange and diffusion of oxygen in crystalline cuprous oxide. J Phys Chem 62(11):1438-1441

Nishikawa T, Okamoto Y, Okada N (1981a) Plastic deformation of Mn-Zn ferrite single crystal. J Soc Mater Sci Jpn 30(337):1012-1018

Nishikawa T, Okamoto Y, Okada N, Nakano H (1981b) Bending creep of Mn-Zn ferrite single crystals. Nippon Kagaku Kaishi (J Chem Soc Jap) 10:1624-1629

O’Bryan H, DiMarcello F (1970) Oxygen diffusion in nickel ferrous ferrite. J Am Ceram Soc 53:413-416

Okamoto Y (1989) Creep deformation mechanisms in oxides and deformation of spinel ferrites. Rheology of Solids and of the Earth Oxford University Press, Oxford pp 83-104

Prunier AR, Hewitt DA (1981) Calculation of temperature-oxygen fugacity tables for $\mathrm{H}_{2}-\mathrm{CO}_{2}$ gas mixtures at one atmosphere total pressure. Geol Soc Am Bull 92(7 Part II):1039-1068

Rabier J, Veyssière $\mathrm{P}$, Grilhé $\mathrm{J}$ (1976) Plastic deformation of $\mathrm{Ni}_{0.66}$ $\mathrm{Fe}_{2.34} \mathrm{O}_{4}$ spinel ferrite single crystals. J Mater Sci 11(1):193-195

Reddy K, Cooper A (1981) Oxygen diffusion in magnesium aluminate spinel. J Am Ceram Soc 64(6):368-371 
Ryerson F, McKeegan KD (1994) Determination of oxygen self-diffusion in åkermanite, anorthite, diopside, and spinel: implications for oxygen isotopic anomalies and the thermal histories of $\mathrm{Ca}$ Al-rich inclusions. Geochim Cosmochim Acta 58(17):3713-3734

Salem AA, Kalidindi SR, Doherty RD (2003) Strain hardening of titanium: role of deformation twinning. Acta Mater 51(14):4225-4237

Siemes H, Hennig-Michaeli C, Martens L (1991) The importance of deformation experiments on minerals for the interpretation of metamorphic ore textures. Ore Geol Rev 6(5):475-483. https:// doi.org/10.1016/0169-1368(91)90042-6

Siemes H, Klingenberg B, Rybacki E, Naumann M, Schäfer W, Jansen E, Rosière C (2003) Texture, microstructure, and strength of hematite ores experimentally deformed in the temperature range $600-1100^{\circ} \mathrm{C}$ and at strain rates between $10^{-4}$ and $10^{-6} \mathrm{~s}^{-1}$. J Struct Geol 25(9):1371-1391

Siemes H, Klingenberg B, Rybacki E, Naumann M, Schäfer W, Jansen E, Kunze K (2008) Glide systems of hematite single crystals in deformation experiments. Ore Geol Rev 33(3):255-279

Siemes H, Rybacki E, Kunze K, Klingenberg B, Naumann M, Brokmeier HG, Jansen E (2010) Development of microstructure and texture of hematite ores deformed to large strain in torsion: Can texture identify the prevailing strength and creep mechanisms during deformation? Adv Eng Mater 12(10):1003-1007

Siemes H, Rybacki E, Klingenberg B, Rosière C (2011) Development of a recrystallized grain size piezometer for hematite based on high-temperature torsion experiments. Eur J Mineral 23(3):293-302

Sievwright R, ONeill HSC, Tolley J, Wilkinson J, Berry A (2020) Diffusion and partition coefficients of minor and trace elements in magnetite as a function of oxygen fugacity at $1150^{\circ} \mathrm{C}$. Contrib Miner Petrol 175:1-21
Terry M, Heidelbach F (2006) Deformation-enhanced metamorphic reactions and the rheology of high-pressure shear zones, Western Gneiss Region. Norway. J Metamorph Geol 24(1):3-18. https:// doi.org/10.1111/j.1525-1314.2005.00618.x

Till J, Moskowitz B (2013) Magnetite deformation mechanism maps for better prediction of strain partitioning. Geophys Res Lett 40(4):697-702. https://doi.org/10.1002/grl.50170

Till JL, Rybacki E, Morales LF, Naumann M (2019) High-temperature deformation behavior of synthetic polycrystalline magnetite. J Geophys Res 124(3):2378-2394

Van Orman J, Crispin K (2010) Diffusion in oxides. Rev Mineral Geochem 72(1):757

Veyssiere P, Rabier J, Garem H, Grilhe J (1978) Influence of temperature on dissociation of dislocations and plastic deformation in spinel oxides. Philosopical Magazine A 38(1):61-79

Wang Y, Huang J (2003) Texture analysis in hexagonal materials. Mater Chem Phys 81(1):11-26

Zhang XQ, Song XY, Chen LM, Xie W, Yu SY, Zheng WQ, Deng YF, Zhang JF, Gui SG (2012) Fractional crystallization and the formation of thick Fe-Ti-V oxide layers in the Baima layered intrusion, SW China. Ore Geol Rev 49:96-108

Zheng Y, Han X, Gao X, Geng X, Chen X, Liu J (2017) Enrichment of iron ores by folding in the BIF-hosted deposit: a case study from the Archean Qian' an iron deposit, North China Craton. Geol J

Publisher's Note Springer Nature remains neutral with regard to jurisdictional claims in published maps and institutional affiliations. 